\title{
L'aver cura di donne è pazzia: una comedia italiana del siglo XVIII y No puede ser de Agustín Moreto*
}

\section{L'aver cura di donne è pazzia: a 17th Century Italian Comedy and No puede ser by Agustín Moreto}

\section{ROBERTA ALVITI}

Università degli Studi di Cassino e del Lazio meridionale Via Sant'Angelo, 1. Cassino (Fr) Italia

r.alviti@unicas.it

Orcid ID 0000-0002-7739-2327

Resumen: La presente contribución se centra Aver cura di donne è pazzia, comedia del dramaturgo florentino Giovan Battista Fagiuoli (166o-1742); hasta la fecha no se había detectado la relación de dicha obra con la comedia de capa y espada No puede ser, escrita hacia 1659 y publicada por primera vez en 1661. La localización del título italiano en un catálogo teatral del siglo XVIII llevó a hipotetizar algún parentesco entre la comedia de Fagiuoli y la de Agustín Moreto; la colación entre los dos textos confirmó el parentesco y se pudo deducir que Fagiuoli fue sustancialmente fiel a la intriga principal de la comedia española, suprimiendo, sin embargo, algunos tramos dramáticos para insertar en su reelaboración subtramas nuevas. La autora ha realizado una tabla comparativa entre los núcleos diegéticos del texto fuente, basándose en un resumen dividido en cuadros numerados y los núcleos diegéticos de la obra italiana, según una sinopsis, dividida en escenas; de la tabla resulta evidente la ampliación del material dramático realizada por Fagiuoli.

Palabras clave: No puede ser. Aver cura di donne è pazzia. Agustín Moreto. Adaptación. Circulación de modelos teatrales.
RECIBIDO: 26 DE MARZO DE 2019 ACEPTADO: 20 DE MAYO DE 2019
Abstract: The present contribution deals with Aver cura di donne è pazzia, a comedy by the Florentine playwright Giovan Battista Fagiuoli (1660-1742). Until today, no parentage has been detected between this text and comedy by Agustín Moreto No puede ser, written in 1659 and first published in 1661. The identification of the Italian title in an eighteenth-century theatrical catalogue lead to speculate that there was a relationship between Fagiuoli and Agustín Moreto's comedies; the collation between these two texts confirmed this relationship, and researchers may infer that Fagiuoli was fundamentally faithful to the main plot of the Spanish comedy, although he suppressed some dramatic segments so as to include new subplots in his re-worked version. This essay features a comparative chart of the diegetic units of the source text, based upon a summary divided in numbered cuadros, and the diegetic units of the Italian text, starting from a synopsis, divided into scenes. This chart highlights Fagiuoli's apparent expansion of the dramatic material.

Keywords: No puede ser. Aver cura di donne è pazzia. Agustín Moreto. Adaptation. Circulation or Theatrical Models.

\footnotetext{
* El presente trabajo se enmarca en varios proyectos, en concreto: el proyecto La obra dramática de Agustín Moreto. IV: Comedias escritas en colaboración, financiado por el Ministerio de Educación y Ciencia y Fondos del Gobierno de España, dirigido por la profesora María Luisa Lobato, el proyecto del Ministerio Italiano PRIN 2015 Il teatro spagnolo (1570-1700) e l'Europa: studio, edizione di testi e nuovi strumenti digitali, dirigido por la profesora Fausta Antonucci y, finalmente, el proyecto Ricezione e circolazione del teatro di Agustín Moreto in Italia, dirigido por la profesora Debora Vaccari y financiado por la Sapienza Università di Roma.
} 


\section{PREMisa}

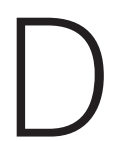

esde hace varias décadas en la producción crítica de interés hispánico se viene destacando la gran cantidad de traducciones de obras dramáticas españolas que se produjeron en Italia en los siglos XVII y XVIII. A partir de los estudios de Profeti que abrieron nuevas y fructíferas rutas de investigación, varios estudiosos se han dedicado, in primis, a detectar una amplia gama de casos individuales; en segundo lugar, a establecer unas directrices teóricas para este campo de investigación y, finalmente, a identificar filológicamente las deudas de los textos italianos con piezas áureas. En particular, los estudios dedicados a autores específicos han individuado en la ciudad de Florencia un contexto privilegiado para la circulación del teatro español.

Precisamente en este ámbito urbano se encuadra L'aver cura di donne è pazzia ovvero Il Cavaliere parigino, comedia escrita por Giovan Battista Fagiuoli, autor y dramaturgo florentino activo entre 1675 y 1742. La lectura de este texto, que no ha gozado de mucha atención por parte de la crítica, ha sacado a la luz un parentesco con la comedia de capa y espada No puede ser, escrita por Agustín Moreto; hasta la fecha, dicho vínculo entre las dos obras había pasado completamente inadvertido para la crítica.

El propósito del presente trabajo es dar a conocer este descubrimiento, proponiendo un primer acercamiento a la obra italiana, y sacar a la luz sus relaciones estructurales con No puede ser.

\section{NO PUEDE SER EN ITALIA}

La comedia de Agustín Moreto No puede ser, según se infiere de algunos avisos contemporáneos, debió de representarse en castellano en el ámbito familiar de Gaspar Guzmán de Haro, vII marqués del Carpio, embajador español ante la Santa Sede desde 1677 hasta 1683. No se conservan libretos en español para documentar la efectiva representación en castellano, pero en la Biblioteca de la Accademia dei Lincei de Roma hay un ejemplar impreso del scenario que es el primero de tres que están basados en la pieza moretiana; este primer canovaccio remite a la puesta en escena en italiano en el palacio del Embajador durante el Carnaval de 1682. El segundo de los scenari, Non può essere, se incluye en la compilación napolitana Gibaldone comico di vari suggetti copiate da me Antonio Pasanti detto Orazio Calabrese en 1700. A los años treinta del siglo XVIII se remonta el tercero de los scenari, Non può essere, ovvero la Donna può ciò che vuole, el cual forma parte del Zibaldone de Placido Adriani. Este texto es muy similar 
al scenario napolitano y, al igual que aquel, se insertan en él multitud de lazzi y se acortan o suprimen algunas escenas del original moretiano con el fin de adaptarlo a las exigencias de la commedia dell'arte (Alviti, en prensa).

Ahora bien, tal y como se apuntó en la "Premisa", hasta hoy se opinaba que la pieza moretiana no había tenido más adaptación italiana que los tres $c a$ novacci que se acaban de mencionar; sin embargo mientras quien escribe se dedicaba al estudio de estos textos, al consultar la Drammaturgia de Leone Allacci, encontró un título, Aver cura di donne è pazzia, di Giovan Battista Fagiuoli (Allacci 130), ${ }^{1}$ que le recordó la comedia moretiana.

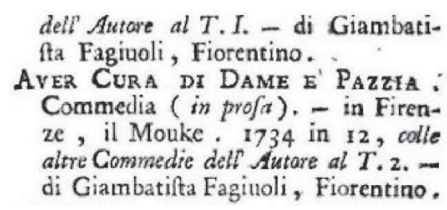

Al leer la obra italiana se pudo comprobar que entre las dos piezas había una vinculación muy estrecha: no podemos hablar de traducción porque entre el texto de Moreto y el de Fagiuoli no se detectan loci paralleli. Aun no tratándose de una traducción ad litteram, se aprecia en la obra italiana la presencia de material dramático derivado de la comedia moretiana. Hay que apuntar que esta vinculación nunca había sido señalada por la crítica, ni en el ámbito italiano ni en el español; una de las posibles razones es el hecho de que en ningún lugar del texto o del paratexto se hace mención de Agustín Moreto.

\section{ARgumento DE No PUEDE SER}

Agustín Moreto debió de componer No puede ser, comedia que refunde El mayor imposible, de Lope de Vega, en torno a 1659; la pieza, que fue impresa por primera vez en la colección Pensil de Apolo, en doce comedias nuevas de los mejores ingenios de España: parte catorce (Madrid, por Domingo García Morrás, 1661, ff. 1r-23v), ha sido recientemente editada por María Luisa Lobato y María Ortega, en el quinto volumen de la Segunda parte de comedias de Moreto, dentro del proyecto de edición crítica e interpretación de la obra dramática del dramaturgo. ${ }^{2}$

1 Para un acercamiento a la fortuna y a las reescrituras italianas de Moreto, ver Alviti y Vaccari.

2 Moreto 2016. Es la edición que se utiliza para este trabajo. 
La acción de la pieza arranca de la aseveración de que el honor de una mujer no puede guardarse si ella misma no consiente en hacerlo; dicha afirmación se hace en una de las reuniones de la academia de doña Ana Pacheco, que recuerda muy de cerca la academia de Nise, la "dama discreta", hermana de la protagonista de La dama boba de Lope de Vega. Doña Ana, de hecho, propone una adivinanza:

Este fuego que arde en mí otro fuego le encendió, que arde también como yo y a un tiempo ardemos ansí. El humo que exhala el fuego conviene a mi perfección, y el cubrirme es por razón de que no le exhale luego; mientras que no me consumo, cuando más tierra me das más me abrigas y arde más, con que he de arrojar más humo; no dejando yo de arder, salir en vapor presumo.

Decid quién soy yo y el humo que guardar no puede ser. (vv. 323-38)

Tras varios intentos de los participantes, don Félix de Toledo acierta con la respuesta a la adivinanza: se trata de la mujer:

El humo denso que exhala es su honor; la tierra luego con que le cubren, es cierto, que son las guardas que tiene su honor; y mientras, queriendo, más guardas ponerle intentan, se enciende más su deseo y crece el daño. De donde se infiere con claro ejemplo, que cuando la mujer quiere, si de su honor no hace aprecio, 
guardarla no puede ser,

y es disparate emprenderlo. (vv. 354-66)

Por otra parte, don Pedro Pacheco, primo y pretendiente de doña Ana, hermano y guardián de una joven mujer soltera, doña Inés, sostiene que el honor de una dama está en manos del caballero que esté encargado de guardarlo. Es más: afirma que será capaz de proteger el honor de su hermana, doña Inés, en cualquier circunstancia; sostiene su opinión con tanto ímpetu que está a punto de desenvainar la espada para batirse con don Félix.

Vista la seguridad de don Pedro, doña Ana decide buscar algún subterfugio para desmentirlo: además, la dama no tiene intención de casarse con don Pedro si él persevera en esta actitud de rigidez y desconfianza hacia las mujeres. Por lo tanto, pide a don Félix que corteje a Inés y la enamore, desmintiendo así la opinión de don Pedro. Tarugo, el criado de don Félix, es el verdadero motor de la acción dramática e inventa una serie de estratagemas para ayudar a su señor a enamorar a Inés. Bajo la apariencia del asistente del sastre, Tarugo consigue acceder a la casa de don Pedro y entregar a doña Inés el retrato de don Félix. Luego, disfrazado de indiano rico y con el nombre de don Crisanto, se hace pasar por amigo de un amigo de don Pedro, quien lo invita a quedarse en su casa, lo cual allana el camino para la entrada de don Félix. Mientras tanto, don Pedro impone a Inés casarse con un amigo suyo, don Diego. Ya en el tramo final de la obra, el último ardid de Tarugo permite el esperado desenlace: el criado, de hecho, convence a doña Inés de que salga de casa con su criada Manuela; las dos, embozadas, acompañadas por Tarugo y don Félix, se dirigen a la casa de este, donde tendrán lugar las bodas entre el joven e Inés. Pero en el camino topan con don Diego y don Pedro, quienes se ofrecen a acompañarlos hasta su casa. Por lo tanto, será el mismo don Pedro quien entregue a su hermana, a la que no reconoce, en manos de don Félix. Todo termina felizmente al reconocer don Pedro su vana confianza. Acepta a don Félix como esposo de doña Inés y doña Ana a su vez consiente la propuesta de don Pedro. Manuela, criada de doña Inés, se casa con Tarugo.

En la tabla 1 se propone una representación esquemática de las relaciones familiares, amo-criado, amorosas y de amistad entre los personajes de $\mathrm{No}_{0}$ puede ser. 


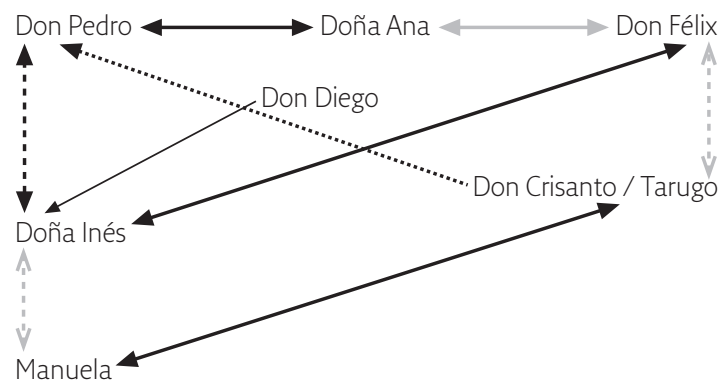

Tabla 1
Amor correspondido

Amor no correspondido

Amistad

Familia

Relación amo-criado

Relación basada en la mentira

\section{FORTUNA DE NO PUEDE SER}

No puede ser tuvo mucho éxito en varios países europeos: de la obra se hicieron, en efecto, una serie de traducciones y reescrituras a lo largo de casi un siglo. ${ }^{3}$ La más antigua de estas, que no tuvo mucha resonancia ni en los escenarios ni en la prensa, fue realizada por Thomas St. Serfe en 1668, con el título

3 Utilizamos los términos traducción y reescritura, tomando como punto de referencia el ensayo de Santoyo, quien parte del presupuesto de que "la traducción teatral presenta características determinadas que la distancian de otros modos traductores. [...] Cualquier otro tipo de escrito, verso o prosa, informativo, literario o técnico, concluye en la letra impresa y en el lector al que se destina, y otro tanto ha de decirse de su correspondiente traducción. El texto dramático no: su teleología es distinta, porque fue creado [...] para vivir y proyectarse más allá del propio texto, y solo cobra esa vida completa cuando este se convierte en teatro ante un público espectador: es la escena, solo en ella, donde el texto se 'realiza' de manera total" (96-97). A continuación, el estudioso apunta: "El texto teatral es una y otra cosa al tiempo: literatura dramática [...] y un texto para la escena. [...] Todo ello hace que un texto se desmembre en dos grandes categorías iniciales, en función, a su vez, de dos ámbitos diferentes: el textual y el escénico. Como texto, puede traducírselo para desempeñar una función exclusivamente textual. Como teatro, puede traducírselo para ser teatro, es decir, para ser a su vez re-traducido de la página al escenario" (97). Opina, luego, que resulta más conveniente utilizar: "el término tradicional, traducción, para designar el estricto transvase intertextual de una pieza dramática"; añade Santoyo: "[En la traducción] comienza y termina el acto de transferencia y por lo mismo carece de proyección escenográfica inmediata" (97); para el estudioso, en cambio "la adaptación tiene un único objetivo: naturalizar teatro en una nueva cultura meta para lograr el efecto equivalente del que habla Newmark; acomodar, adecuar y ajustar particulares a las expectativas de un colectivo distinto, separado del primero por un amplio gap socio-cultural de tempo o espacio, o de ambos a la vez. El adaptador salva ese distanciamiento y reduce el handicap previsible de recepción en la audiencia meta" (104); para llegar a una precisión que cumpla con las necesidades terminológicas del presente trabajo, sin embargo, hay que acudir a la ulterior matización propuesta por Santoyo, cuando habla de reescritura: "Lo que muchos han venido definiendo desde antiguo 'adaptación libre' no pasa de ser una reescritura [...]. Aquí el 'adaptador' se desvincula del texto, forma y parámetros del original para, sin soltar del todo las amarras que lo unen a él, proceder a tales modificaciones que bajo muchos aspectos el producto resultante no equivale ya del que deriva. [...] Domina en la rescritura el mimetismo del momento (literario, socio-político e incluso teatral) por el que pasa la cultura meta, que se convierte así en el rasgo dominante y al que se subordina la idiosincrasia del original" (105). 
Tarugo's Wiles, or the Coffee House. En cambio, Sir Courtly Nice or It cannot be, obra de John Crowne, publicada en 1685, fue muy apreciada por el público inglés de la época. En la redacción de esta pieza, además, Crowne utilizó tramos diegéticos de otra pieza moretiana, El lindo don Diego.

Un siglo después, en 1770, se editó una versión en lengua francesa, $L a$ chose impossible, en una colección de obras teatrales españolas realizada por Simon-Nicholas Henri Linguet. Según se lee en el Prólogo de la citada edición: "Se trata de una traducción literal al francés sin mayor interés artístico que no está dedicada a la escena, sino que tiene más bien el fin de dar a conocer al lector francés las obras españolas de mayor éxito" (52).

\section{Argumento de L'AVER CURA DI DONNE È PAZZIA}

Aver cura di donne è pazzia ovvero Il Cavaliere parigino se publicó en 1734 en el tomo segundo de las comedias de Giovan Battista Fagiuoli, publicado en Lucca por Salvatore e Giandomenico Marescandoli. Es el texto que se maneja en el presente trabajo.
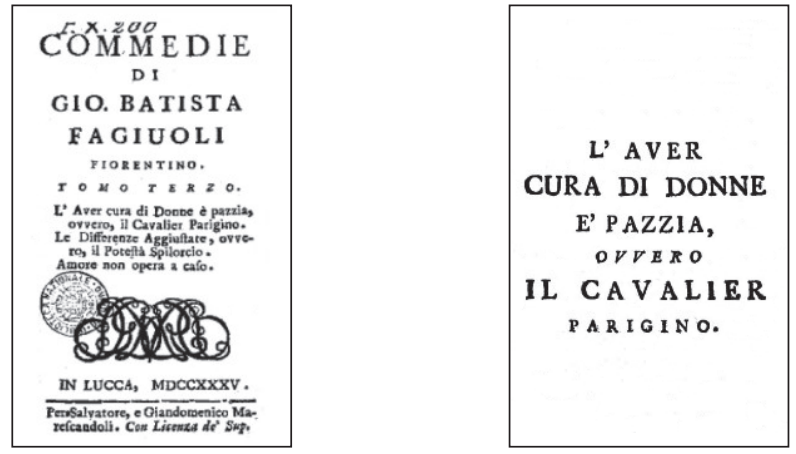

Fagiuoli fue en su época personaje de renombre; sin embargo, su figura y su obra no han sido muy tratadas por la crítica antigua y la contemporánea. ${ }^{4}$ Por lo que se refiere a su actividad como dramaturgo, hay que destacar que forma parte de los llamados "pregoldonianos", participando en la reforma teatral que estaba encaminada a cambiar las formas de interpretar y los gustos del públi-

4 Trabajos más antiguos como los de Bencini y Bolsi constituyen una excepción (téngase en cuenta, por otra parte, que la perspectiva metodológica adoptada por estos estudiosos lógicamente está superada en más de un aspecto); tampoco buscando ensayos que analicen en general la obra del dramaturgo es fácil encontrar resultados recientes si se excluyen los de Binni, Decroisette, Foggi, Pecori (ed.), Turchi 1985. Para una estudio biográfico detallado, ver Foggi. 
co, proponiendo una comedia que imitara la vida, incluso con intenciones de denuncia social; una comedia que, además, se transformara en escuela de comportamiento, en detrimento de la banalidad psicológica y la simplicidad narrativa del Teatro del Arte. Pero la novedad más importante de esa reforma consistía en la primacía del texto escrito, con líneas narrativas y psicológicas bien definidas, en el que se contemplasen un planteamiento, un desarrollo y un epílogo de la acción con intención moralizante. Además, se trataría de un texto que los actores tendrían que aprender de memoria, todo ello sin renegar completamente de las máscaras y los canovacci de la commedia dell'arte, cuya aportación el autor tendría que suministrar inteligentemente para no disgustar al público, que estaba acostumbrado a ellos. ${ }^{5}$ En las distintas comedias de Fagiuoli se aprecia, de hecho, por primera vez un replanteamiento de las estructuras del teatro cómico basado en la racionalización de la trama y la exclusión parcial de las máscaras. Resulta muy significativo, por lo tanto, su papel en la reforma de la escena italiana en la transición hacia el drama dieciochesco.

En las páginas que siguen, sin embargo, no se tomarán en consideración la peculiariades de Fagiuoli como dramaturgo, sino que se tratará, haciendo hincapié en la obra de partida, No puede ser, de analizar los mecanismos de reescritura del texto moretiano por parte del dramaturgo italiano.

La obra de Fagiuoli va precedida por un elenco de Interlocutori, en el que se indica también el papel que desempeña cada uno de los personajes:

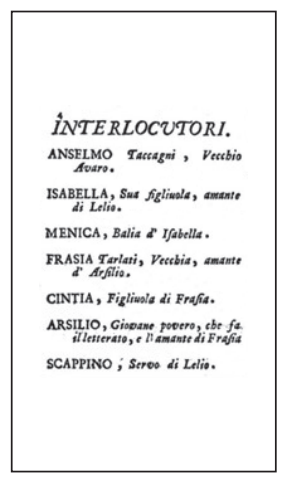

Tras la lista de dramatis personae aparece el argomento, que reza:

5 Para un panorama sobre los dramaturgia en la época de Fagiuoli, ver la base de datos Archivo del teatro pregoldoniano disponible en la página web http://www.usc.es/goldoni/. Fecha de acceso: 15/02/2019. 
Frasia Tarlati, vedova, che vanamente pretende di bella e virtuosa, procura di rilevare Cintia, sua figliola, con tutta la libertà maggiore; e questa, non prevalendosi punto né dell'esempio della Madre, né della di lei mala educazione, finalmente si fa Monaca. Por lo contrario, Isabella, figliuola, d'Anselmo Taccagni, da esso con somma gelosia custodita, non ostante, s'innamora di Lelio, e per l'astuzie e rigiri di Scappino, ed assistita ancora dalla Menica, sua balia, vecchia accorta, della quale fidavasi Anselmo, vien questi ridotto a consegnar di propria mano la figliola all'amante, col quale si sposa; come la vecchia Frasia pure si rimarita con Arsilio Avvampati, giovane povero e che fa il virtuoso. Onde si conclude, che [come queste non vogliano da per loro] L'AVER CURA DI DONNE Ė PAZZIA. (Fagiuoli 5-6)

Dicha obra comienza con la confesión del joven Lelio a Scappino, su nuevo criado, del amor que siente hacia Isabella, hija de Anselmo Taccagni. Este es un viejo avaro que obliga a la joven a vivir aislada, porque quiere impedir que se enamore de alguien y se case, gastando su dinero en la dote. Por esta razón, el propio Anselmo ni siquiera había permitido que Isabella lo acompañara a la Academia celebrada el día anterior en la casa de Frasia, donde estaba presente también Lelio, hijo de esta última, temiendo que el joven, al conocerla, la cortejara y la enamorara. Scappino, entonces, ofrece su ayuda a su amo para organizar un encuentro con Isabella. Para ello se introduce en casa de Anselmo disfrazado de chincagliere, o sea, un vendedor de quincallería. Una vez allí, entrega a Isabella un retrato de Lelio y comprueba que esta corresponde a los sentimientos del joven. Luego, de acuerdo con Menica, nodriza de Isabella, organiza una cita nocturna entre Lelio y la joven, aprovechando la ausencia momentánea de Anselmo de la casa. Durante este encuentro, Scappino consigue que Isabella le entregue una de las cartas enviadas a Anselmo por Pancrazio Taccagni, su hermano. A partir de esta carta, escribe otra a Anselmo fingiendo ser Pancrazio, pidiendo que hospede en su casa a un amigo suyo, Monsù Gian Gian delle Tantesciose, asegurando que este compensaría adecuadamente la hospitalidad. Anselmo decide acogerle, ignorando que en realidad este huésped no es sino el propio Scappino, quien en este papel remedia la falta de atención de Isabella, que había dejado el retrato de Lelio a la vista de Anselmo; finge, por lo tanto, que se trata del retrato de un joven que él busca para casarlo con una pariente suya. Luego aparecen Frasia, madre de Lelio y Cinzia, un personaje antitético a Anselmo. De hecho, ella trata constantemente de alentar a Cinzia para que salga de casa y busque a un hombre con quien pueda casarse, pero la joven parece muy reacia a la idea. En el último acto, Scappino traza un plan para per- 
mitir que Isabella y Menica salgan de la casa sin que Anselmo se dé cuenta; por este motivo, el criado simula una enfermedad grave después de encontrarse en casa con dos mujeres tapadas. De hecho, Monsù Gian Gian dice continuamente sentir una tremenda repulsión hacia las mujeres; Anselmo, asumiendo que las dos mujeres son Frasia y Cinzia, decide despedirlas rápidamente, preocupado por las condiciones de salud de su huésped. Saliendo de la puerta de la casa, Anselmo se encuentra con Lelio y Arsilio, el pretendiente de Frasia, y decide entregarles a las dos mujeres tapadas sin darse cuenta de que debajo del embozo se esconden su hija Isabella y Menica. Los cuatro deciden ir a casa de Frasia, donde Lelio se casa con su enamorada. En esto, llega Anselmo que se siente desesperado al darse cuenta de la desaparición de su hija y de la nodriza. Se le revela el engaño y el viejo se ve obligado a aceptar a regañadientes el matrimonio entre su hija y Lelio. Al final de la obra, Arsilio también decide casarse con Frasia, mientras que Cinzia declara que quiere hacerse monja. Tanto Anselmo como Frasia habían imaginado un futuro diferente para sus hijas y, al ver que sus expectativas no se han realizado, llegan a la conclusión de que "Aver cura di donne è pazzia", o sea, "cuidar de mujeres es una locura".

En la tabla 2 se propone una representación esquemática de las relaciones familiares, amorosas y de amistad entre los personajes de Aver cura di donne è pazzia.

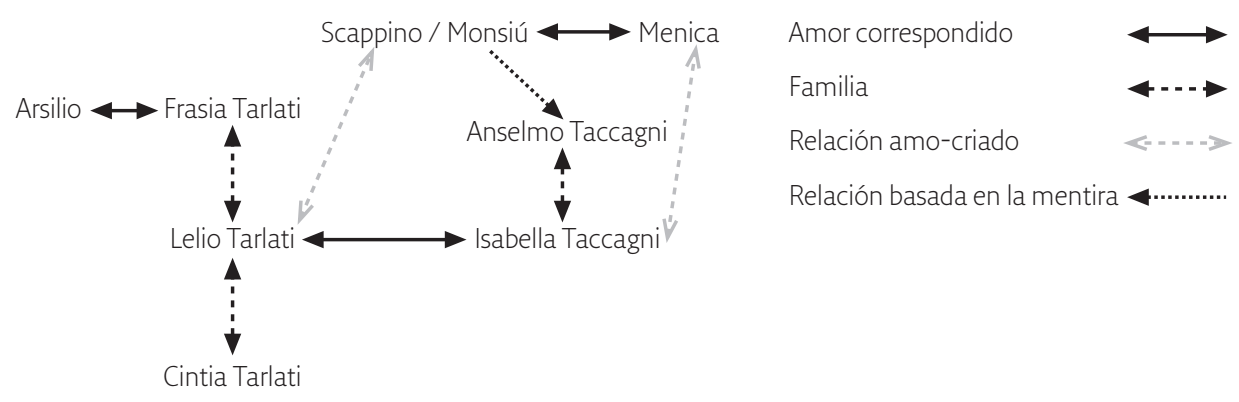

Tabla 2

\section{AFINIDADES Y DIVERGENCIAS ENTRE LAS DOS OBRAS}

El primer elemento significativo que emerge del análisis de la comedia de $\mathrm{Fa}$ giuoli es que está escrita, según la praxis de la época, en prosa; en segundo lugar, se observa que Fagiuoli conserva la estructura en tres jornadas, dividiendo el texto en escenas según la regla tradicional. La primera jornada tiene 22 escenas, así como la segunda y la tercera 24: en total son 68 escenas. 
Según se lee en el listado de los Interlocutori, casi todos los personajes del texto español están presentes en la obra italiana, exceptuando algunas figuras de músicos y criados, y la de Alberto, pariente de don Pedro. Por lo que se refiere a don Diego, uno de los dos segundos galanes, que en el hipotexto desempeñaba el papel del "galán suelto" (Serralta) y veía frustradas sus aspiraciones amorosas y matrimoniales, cabe señalar que sus funciones actanciales recaen sobre el personaje de Arsilio, el joven pretendiente de Frasia, madre de Lelio y Cinzia. Arsilio tiene el papel del cicisbeo, figura característica del siglo XVIII, también llamado cavalier servente, que acompañaba a una dama, sirviéndola galantemente en todo lo que podía ser necesario durante el día. A veces, el contrato de matrimonio preveía la existencia de uno o más cicisbei. Era una figura marginal de la nobleza; generalmente se trataba de un joven aristocrático pobre que emprendía esta "carrera" para gozar de beneficios que no hubiera podido tener de otra manera. Acabó por ser considerado la manifestación patente de la decadencia moral italiana. ${ }^{6}$ Por otra parte, en los personajes de madre e hija, se desdoblan las características y la función actancial de Ana Pacheco. El viejo Arsilio parece ser una variante de Pantalone, tacaño caballero de mediana edad, cuya obstinación incita a las mujeres de su casa a engañarle. Los cambios introducidos en la comedia de Fagiuoli, por lo que atañe a las dramatis personae, se pueden apreciar en el esquema que aparece a continuación:
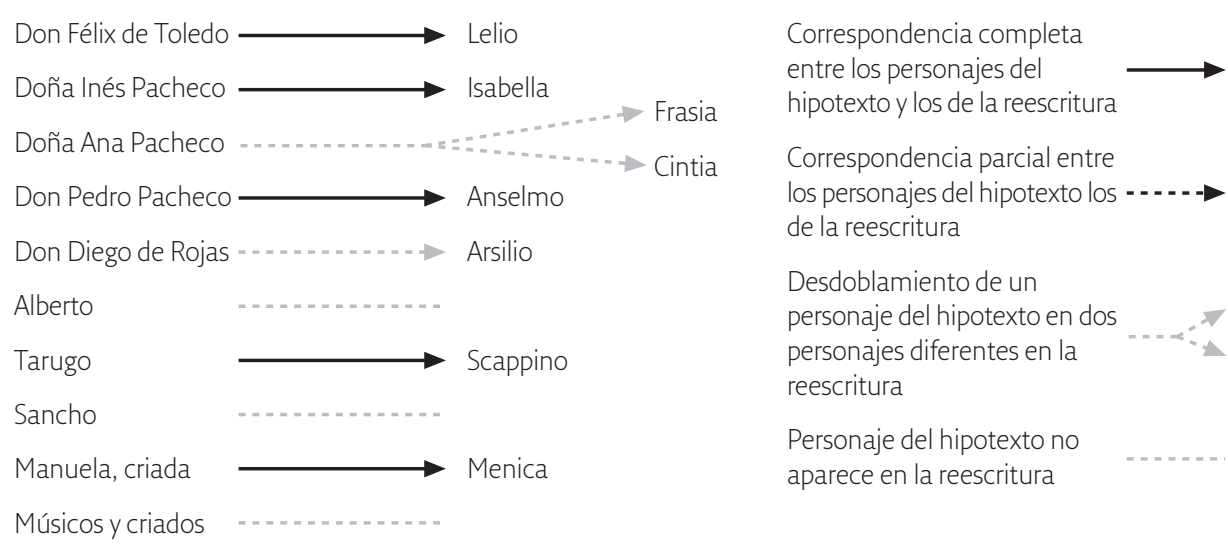

Tabla 3

6 Para la figura del cicisbeo en el teatro desde Fagiuoli hasta Goldoni, ver Turchi 2015. 


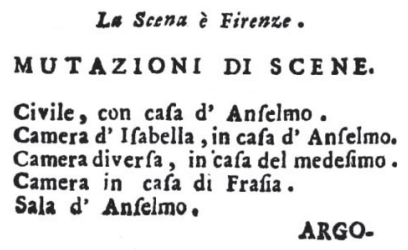

Al final del listado de los Interlocutori aparece una indicación que informa de que "La scena è Firenze" y se indican las "Mutazioni di scene", o sea los distintos contextos espaciales en los que se ambienta la obra. ${ }^{7}$

Las acotaciones son, en su mayoría, lacónicas: señalan los personajes presentes en el escenario y solo ocasionalmente sitúan la acción, de manera muy escueta, en un contexto espacial y/o cronológico; también pueden dar indicaciones a propósito del vestuario.

Como se puede observar en la tabla sinóptica presentada al final del trabajo, en el desarrollo dramático de la pièce italiana, Fagiuoli, aun conservando una fidelidad sustancial a la intriga principal de la comedia española, suprime algunos tramos dramáticos (la relación entre doña Ana y don Pedro, el intento de este de casar a su hermana con don Diego) para insertar en su rifacimento subtramas nuevas (la presencia de la viuda, Frasia, y sus amoríos con el cicisbeo, la hija de la viuda, hermana del protagonista y su relación conflictual con madre; la antipatía y las discuniones entre Frasia y Arsilio, padre de la primera dama, etc.). Sin embargo, los subplots introducidos por Fagiuoli encajan casi milimétricamente con el tramo principal de la estructura dramática moretiana.

El primer elemento en común entre las dos piezas es el arranque: ambos textos empiezan, ex abrupto con un diálogo entre el galán y su criado (don Félix-Tarugo y Lelio-Scappino); sin embargo, en esta secuencia se manifiesta la primera diferencia: Lelio se nos presenta ab origine enamorado de Isabella, a diferencia de lo que sucede en la otra comedia, donde Félix empieza a cortejar a doña Inés bajo petición de doña Ana, enamorándose de veras solo de manera progresiva. Desde esta perspectiva, la relación entre don Félix e Isabella parece reducirse a un medio útil para demostrar la imposibilidad de guardar una mujer, a menos que no sea ella misma quien lo desee, y lograr el objetivo de desilusionar a don Pedro.

7 Con la denominación civile se entiende un escenario exterior, urbano. 
En el hipotexto moretiano, tras el diálogo entre amo y criado, se coloca la secuencia de las academias, que en No puede ser tiene lugar en la casa de Ana Pacheco. Es precisamente durante este encuentro cuando se habla de la imposibilidad de guardar una mujer. En el caso de la comedia moretiana, el tema se introduce con un artificio metaliterario, o sea, a través un poema compuesto por la misma Ana Pacheco. En el texto italiano, en cambio, la secuencia de la academia, que se realiza en casa de Frasia, no se escenifica, sino que se alude a ella como un acontecimiento ocurrido la noche anterior, a través del relato de varios personajes. Sin embargo, aunque el episodio no aparezca concretamente en la representación, su simple mención, en el incipit, es un indicio textual importante que indica el parentesco de las dos obras. Hay que señalar que en la comedia italiana, el tema del honor aunque axial en el desarrollo estructural de la pieza, no es tan debatido desde un punto de vista retórico, como ocurre en No puede ser.

Otro elemento en común está representado por el motivo del retrato que, en ambos casos, el sirviente entrega a la dama protagonista de la intriga amorosa. Cabe señalar que en la comedia moretiana hay un intercambio de retratos entre Félix e Inés, mientras que en la obra de Fagiuoli, Lelio envía su retrato a Isabella, pero no lo contrario. Con el fin de introducirse en casa de la dama y entregar dicho retrato, tanto Tarugo como Scappino tienen que disfrazarse para no ser reconocidos por el pariente varón de la dama, guardián de su honor; en ambos casos, el retrato, que le permite al criado descubrir el amor de las damas hacia los galanes, acabará, por pura casualidad, en manos del hermano/padre de la dama, lo que contribuirá a un aumento de las sospechas hacia la dama que pretende vigilar.

Al final, sin embargo, será el propio criado quien aplaque la ira y los temores del hermano/padre de la dama, reclamando como suyo el retrato del $c a-$ sus belli. De hecho, al introducirse por segunda vez en la casa de la protagonista femenina, gracias a un nuevo disfraz, dice que se trata del retrato que le hacía falta para individuar al joven que querrá casar con una pariente suya. Precisamente el disfraz es uno de los temas principales en las comedias examinadas. En ambos casos, de hecho, el sirviente se disfraza dos veces para poder entrar en varias ocasiones en la casa de la dama. En particular, en No puede ser Tarugo se disfraza antes de sastre y luego de caballero indiano. En Aver cura di donne è pazzia, por otra parte, Scappino se camufla de chincagliero y de caballero parigino. 
En lo relativo a los primeros disfraces utilizados, hay una divergencia entre las dos obras: Tarugo actúa bajo las apariencias de un sastre y Scappino bajo las de un comerciante, o sea un chincagliere. Sin embargo, en Aver cura di donne è pazzia, Scappino en travesti intenta vender una serie de objetos que están relacionados con la figura del sastre, o sea un anillo de costura, agujas, alfileres, etc. Además, en No puede ser, Tarugo utiliza unas gafas para evitar que don Pedro le reconozca y en la comedia italiana, entre otras cosas, Scappino le vende al viejo Anselmo precisamente unas gafas.

En el curso del desarrollo dramático de ambas piezas, tanto Scappino como Tarugo, al introducirse por segunda vez en casa de la dama se disfrazan de caballero "extranjero", un indiano en el caso del hipotexto moretiano y un parisino en la comedia de Fagiuoli, lo que explica el subtítulo de la obra, y en los dos casos el criado disfrazado utiliza una carta de presentación fingida, al parecer escrita por un pariente de don Pedro y Anselmo. En realidad, se trata de cartas escritas por los mismos criados, tomando como modelo las misivas que un pariente había enviado realmente a los dos.

Además, ya en casa de las damas, para no despertar sospechas, tanto Scappino como Tarugo fingen tener tremenda repulsión hacia las mujeres, pretendiendo que tan solo mirar a una mujer les provoca terribles malestares. De esta manera, tanto don Pedro como Anselmo no tienen motivo para temer por el honor de la dama de la casa.

En el tramo final de No puede ser, según se señala en el resumen, Tarugo urde un plan para permitir que Inés y Manuela salgan de la casa sin que don Pedro se dé cuenta; la misma estratagema se utiliza en Aver cura di donne è pazzia, con la única diferencia de que en este caso es el propio Anselmo quien persigue a las dos figuras tapadas por la casa y no sus criados. En ese momento, Anselmo pondrá a su hija, una de las dos figuras embozadas, en manos de Lelio, que está ahí afuera, recomendándole que cuide de ellas.

Por lo tanto, sea el hipotexto español sea la adaptación italiana, terminan con el matrimonio de los dos jóvenes amantes y con don Pedro y Anselmo, quienes se resignan y reconocen su error, o sea, que "no puede ser guardar a una mujer".

Aunque en ninguna parte del texto se menciona a Agustín Moreto, en consideración del sustancial respeto de los núcleos diegéticos fundamentales del modelo español, hay fundados motivos que autorizan a suponer que Aver cura di donne è pazzia deriva de No puede ser y, al compulsar la obra italiana con 
las reescrituras inglesas y la traducción francesa, también se puede afirmar que la derivación de la obra moretiana es directa. Lo que está atestiguado, además, por el título de la obra italiana, que es muy parecido al del texto fuente, aunque con cierta traslación semántica, ya que la expresión italiana aver cura no se corresponde exactamente con guardar, en el sentido de vigilar, sino que, más bien tiene el sentido de cuidar de. Además, el título italiano recuerda muy de cerca los versos finales del soneto pronunciado por don Félix: "que cuando la mujer quiere, / si de su honor no hace aprecio, / guardarla no puede ser, / y es disparate emprenderlo" (vv. 363-66). ${ }^{8}$

Desde luego, el aspecto de la conservación de material dramático merece ser examinado en un futuro trabajo, así como la evaluación de las modificaciones introducidas, para tratar de individuar un eventual paradigma de evolución de teatro europeo hacia las nuevas formas neoclásicas. De la misma manera, sería provechoso intentar averiguar la envergadura del conocimiento que Fagiuoli tuvo del teatro español y si utilizó otras piezas áureas como fuente de inspiración para sus obras dramáticas.

De momento, la presentación de los nudos y motivos dramáticos principales que, mutatis mutandis, comparten las dos obras se complementa con una tabla sinóptico-comparativa que aparece a continuación; en ella se cotejan los núcleos diegéticos del texto fuente, utilizando la sinopsis dividida en cuadros numerados 9 que aparece en el Prólogo de la edición de Lobato y Ortega (7477), con los núcleos diegéticos de la obra italiana, según un resumen, dividido en escenas, elaborado por quien escribe. De la tabla resulta evidente la ampliación del material dramático realizada por Fagiuoli.

La sinopsis de las dos comedias se coloca en dos columnas distintas: los recuadros marcados por tres asteriscos, indican las relaciones de interpolación y de supresión de segmentos dramáticos entre la pièce italiana y No puede ser; de la misma manera, algunas partes de la sinopsis de la obra moretiana que van en cursiva, dentro de algunos de los recuadros, se refieren a partes de la intriga no incorporadas por Fagiuoli en su reescrituta. En el caso en que los diferentes nudos dramáticos se coloquen en puntos distintos en los dos plots, se conectan a través de una línea.

8 La cursiva es nuestra.

9 Adoptando la terminología y la propuesta de segmentación de obras teatrales áureas de Ruano de la Haza (291-94), por "cuadro" se entiende un segmento de texto marcado por una variación del espacio y del tiempo dramático, y asociado a un cambio total de los personajes en escena, lo que produce un momentáneo vacío del tablado. 


\section{TABLA SINÓPTICO-COMPARATIVA}

Aver cura di donne è pazzia

ATTO PRIMO

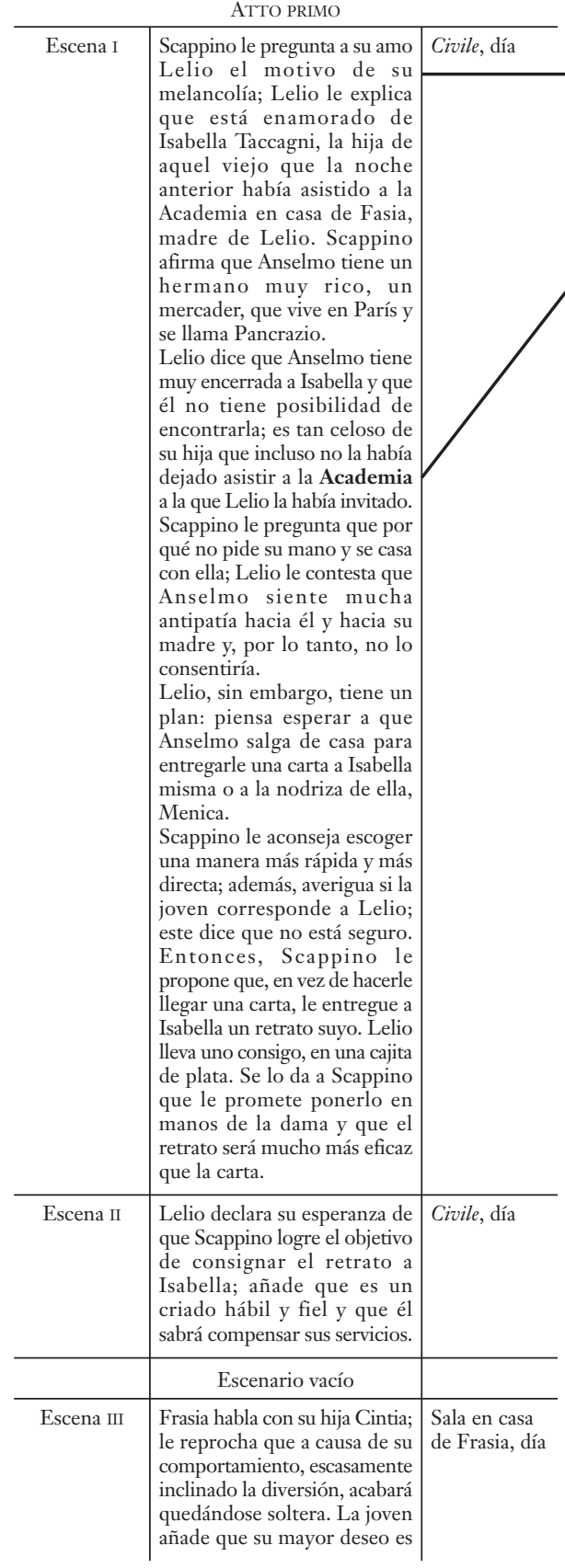

No puede ser guardar una mujer

JORNADA PRIMERA

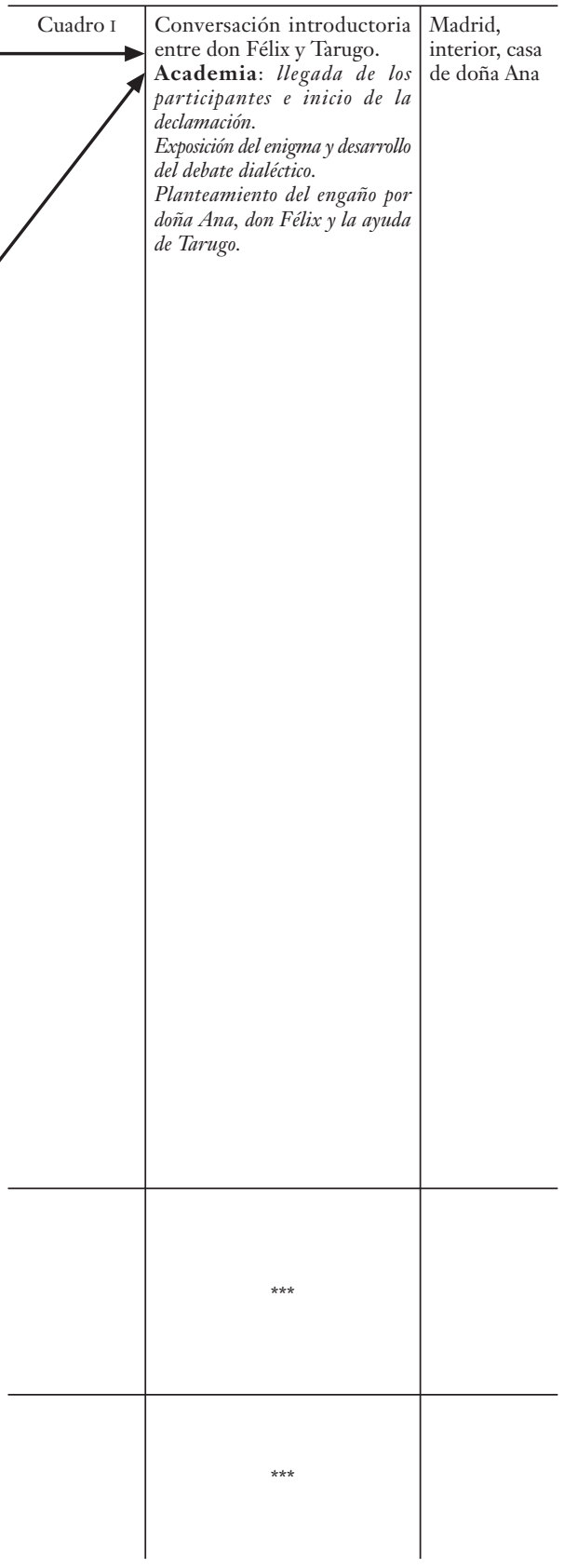




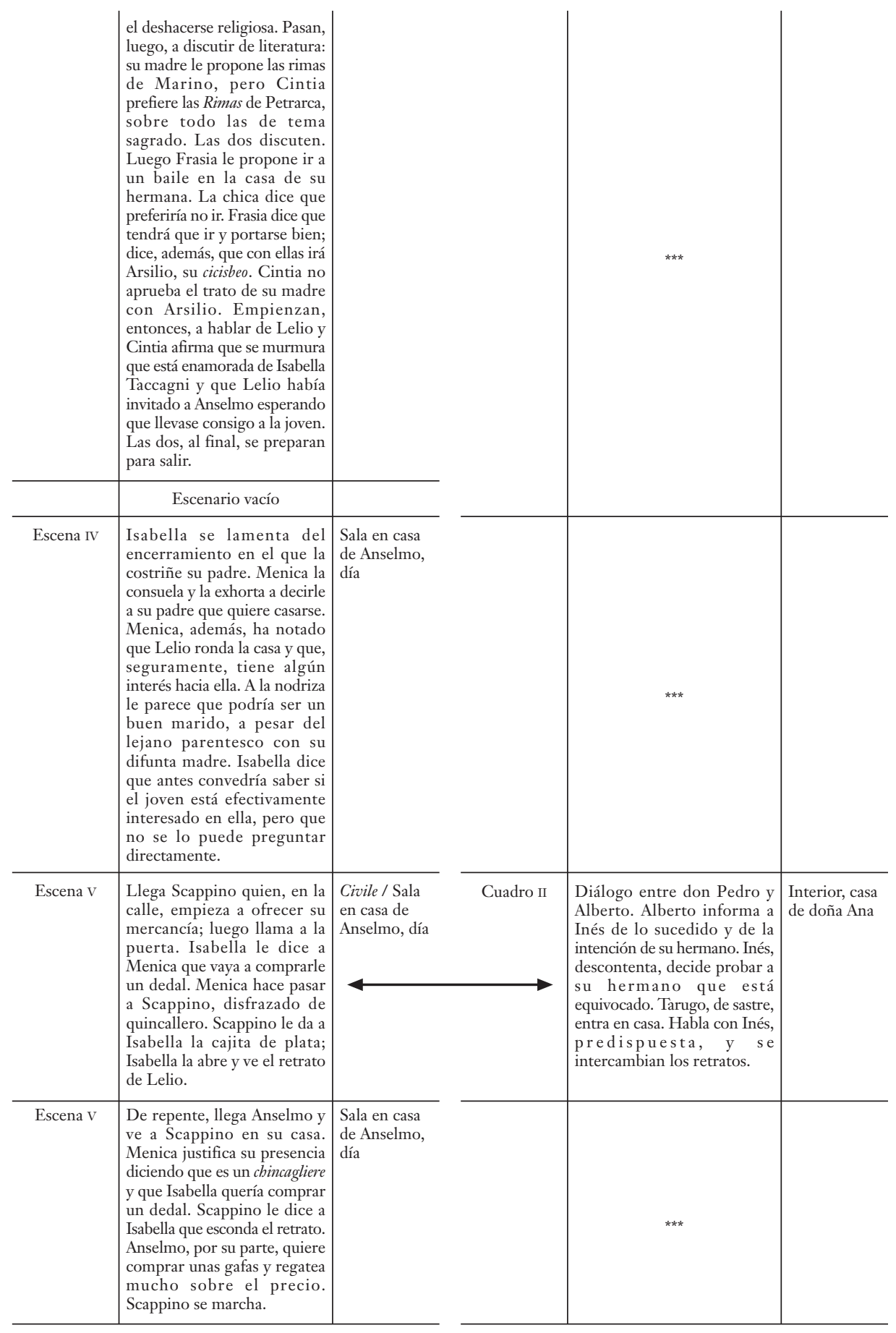


ALVITI. L'AVER CURA DI DONNE È PAZZIA Y NO PUEDE SER

\begin{tabular}{|c|c|c|}
\hline Escena VI & $\begin{array}{l}\text { Anselmo reprocha a Isabella } \\
\text { por haber dejado entrar a un } \\
\text { desconocido en casa. }\end{array}$ & $\begin{array}{l}\text { Sala en casa } \\
\text { de Anselmo, } \\
\text { día }\end{array}$ \\
\hline Escena VIII & $\begin{array}{l}\text { Menica, Anselmo e Isabella } \\
\text { siguen discutiendo sobre la } \\
\text { presencia del chincagliere en } \\
\text { casa. Anselmo se marcha. }\end{array}$ & $\begin{array}{l}\text { Sala en casa } \\
\text { de Anselmo, } \\
\text { día }\end{array}$ \\
\hline Escena VIII & $\begin{array}{l}\text { Menica le explica a Isabella } \\
\text { que el chincagliere no es sino } \\
\text { el criado de Lelio y que el } \\
\text { joven está enamorado de ella; } \\
\text { querría, por lo tanto buscar la } \\
\text { ocasión para hablarle. Menica } \\
\text { le sugiere que los dos se } \\
\text { encuentren por la noche, en } \\
\text { la ventana de la joven, cuando } \\
\text { Anselmo duerma o bien, } \\
\text { cuando esté fuera de casa. } \\
\text { Isabella sigue contemplando } \\
\text { el retrato de Lelio. }\end{array}$ & $\begin{array}{l}\text { Sala en casa } \\
\text { de Anselmo, } \\
\text { día }\end{array}$ \\
\hline Escena IX & $\begin{array}{l}\text { Menica le dice a Isabella que } \\
\text { el quincallero era Scappino, } \\
\text { criado de Lelio. Menica le dice } \\
\text { que será él quien la ayudará a } \\
\text { encontrarse con Lelio. Las dos } \\
\text { hablan de la severidad de } \\
\text { Anselmo y de las perfecciones } \\
\text { del joven. }\end{array}$ & $\begin{array}{l}\text { Sala en casa } \\
\text { de Anselmo, } \\
\text { día }\end{array}$ \\
\hline Escena $\mathrm{x}$ & $\begin{array}{l}\text { Anselmo ve a Isabella que } \\
\text { esconde algo plateado en el } \\
\text { bolsillo. La joven le dice que } \\
\text { es un pastelito con un glaseado } \\
\text { color de plata. Anselmo, ya a } \\
\text { punto de salir., le recomienda } \\
\text { a la nodriza que no deje entrar } \\
\text { a nadie. Menica le contesta } \\
\text { que nada más salir él cerrará } \\
\text { la puerta con llave. }\end{array}$ & $\begin{array}{l}\text { Sala en casa } \\
\text { de Anselmo, } \\
\text { día }\end{array}$ \\
\hline \multirow[t]{2}{*}{ Escena XI } & $\begin{array}{l}\text { Menica y Isabella hablan del } \\
\text { trance peligroso por el que } \\
\text { han pasado. Están muy } \\
\text { aliviadas porque Anselmo no } \\
\text { se ha dado cuenta del retrato. }\end{array}$ & $\begin{array}{l}\text { Sala en casa } \\
\text { de Anselmo, } \\
\text { día }\end{array}$ \\
\hline & Escenario vacío & \\
\hline Escena XII & $\begin{array}{l}\text { Cintia y Frasia se preparan } \\
\text { para ir a la fiesta en casa de la } \\
\text { hermana de esta última. }\end{array}$ & $\begin{array}{l}\text { Sala en casa } \\
\text { de Frasia, } \\
\text { tarde/noche }\end{array}$ \\
\hline Escena XII & $\begin{array}{l}\text { Entra Arsilio. Cintia insiste } \\
\text { para dejar solos a su madre y } \\
\text { a su cicisbeo. }\end{array}$ & $\begin{array}{l}\text { Sala en casa } \\
\text { de Frasia, } \\
\text { tarde/noche }\end{array}$ \\
\hline Escena XIV & $\begin{array}{l}\text { Arsilio luce toda su erudición } \\
\text { para enamorar a Frasia. Esta } \\
\text { deja entender que le gustaría } \\
\text { volverse a casar. Arsilio, por } \\
\text { su parte, afirma que ninguna } \\
\text { mujer querrá casarse con él } \\
\text { por ser tan pobre. }\end{array}$ & $\begin{array}{l}\text { Sala en casa } \\
\text { de Frasia, } \\
\text { tarde/noche }\end{array}$ \\
\hline Escena XV & $\begin{array}{l}\text { Arsilio llama a Cintia. Frasia } \\
\text { reprocha a su hija porque no } \\
\text { está vestida de manera } \\
\text { conveniente para la fiesta. } \\
\text { Cintia le contesta que no le }\end{array}$ & $\begin{array}{l}\text { Sala en casa } \\
\text { de Frasia, } \\
\text { tarde/noche }\end{array}$ \\
\hline
\end{tabular}

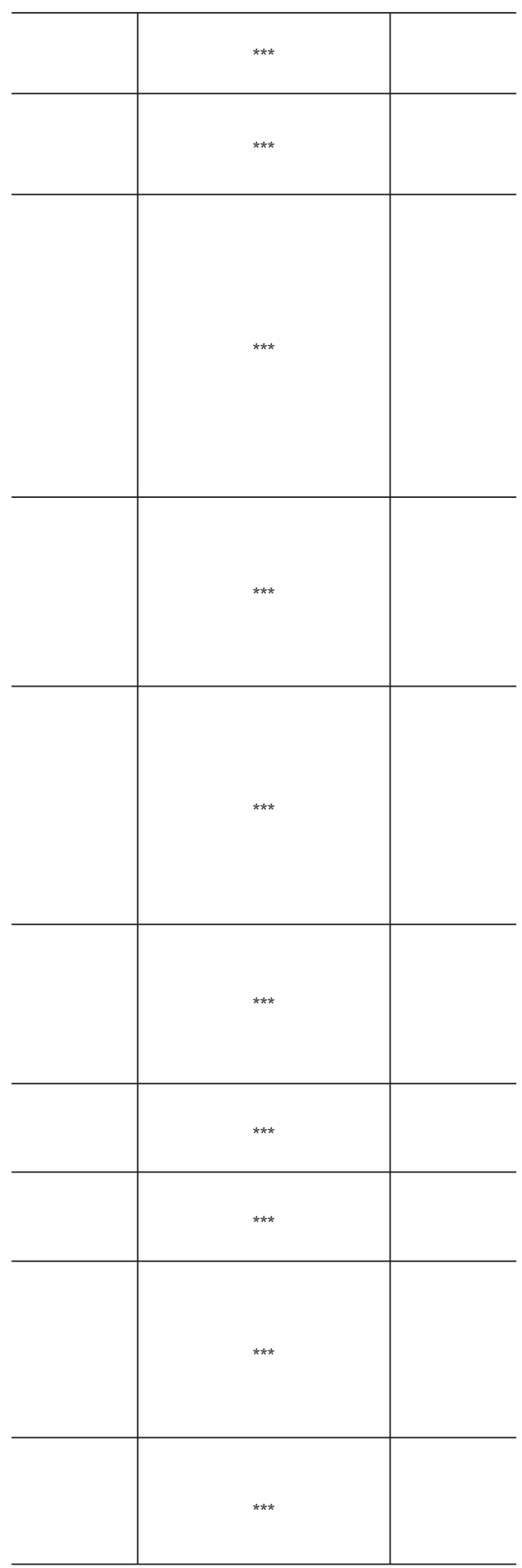


ALVITI. L'AVER CURA DI DONNE È PAZZIA Y NO PUEDE SER

\begin{tabular}{|c|c|c|}
\hline Escena XV & $\begin{array}{l}\text { importa parecer guapa porque } \\
\text { no quiere casarse. Arsilio, en } \\
\text { un aparte, dice que espera que } \\
\text { Frasia se decida a casarse con } \\
\text { él. }\end{array}$ & $\begin{array}{l}\text { Sala en casa } \\
\text { de Frasia, } \\
\text { tarde/noche }\end{array}$ \\
\hline & Escenario vacío & \\
\hline Escena XVI & $\begin{array}{l}\text { Lelio y Scappino están cerca } \\
\text { de la casa de Isabella. } \\
\text { Scappino, tal y como habían } \\
\text { concertado con Menica, silba } \\
\text { para avisar a las dos mujeres. }\end{array}$ & Civile, noche \\
\hline Escena XVII & $\begin{array}{l}\text { Menica se asoma a la ventana } \\
\text { y dice que va a llamar a Isabella. }\end{array}$ & Civile, noche \\
\hline Escena XVIII & $\begin{array}{l}\text { Coloquio amoroso entre Lelio } \\
\text { e Isabella. En esto, Scappino } \\
\text { llega y le pide a Isabella que } \\
\text { se dé prisa en buscar una de } \\
\text { las cartas que Anselmo recibe } \\
\text { de su hermano Pancrazio, que } \\
\text { vive en París. Scappino les } \\
\text { explica que quiere escribir una } \\
\text { carta a Anselmo, imitando la } \\
\text { firma de Pancrazio. En eso, } \\
\text { vuelve Anselmo. }\end{array}$ & $\begin{array}{l}\text { Civile / } \\
\text { ventana de la } \\
\text { casa de } \\
\text { Anselmo, } \\
\text { noche }\end{array}$ \\
\hline Escena XIX & $\begin{array}{l}\text { Llega Anselmo: se ha olvidado } \\
\text { de la linterna y camina a ciegas. } \\
\text { Lelio y Scappino le reconocen., } \\
\text { Anselmo encuentra una luz. } \\
\text { Los dos tienen que huir, } \\
\text { aunque Isabella podría estar a } \\
\text { punto de llegar con la carta. }\end{array}$ & Civile, noche \\
\hline Escena $\mathrm{Xx}$ & $\begin{array}{l}\text { En eso, llegan a la misma calle } \\
\text { Frasia, Arsilio y Cintia, que } \\
\text { discuten entre sí. Anselmo } \\
\text { critica, en varios apartes, a } \\
\text { Frasia. }\end{array}$ & Civile, noche \\
\hline Escena XXI & $\begin{array}{l}\text { Llega Isabella con la carta. } \\
\text { Frasia y Cintia siguen } \\
\text { discutiendo y Anselmo } \\
\text { continúa criticando a Frasia. } \\
\text { Anselmo llega hasta la puerta } \\
\text { de su casa. Isabella lo ve } \\
\text { acercarse, pero cree que es } \\
\text { Lelio o Scappino. Este para } \\
\text { entretener a Anselmo remeda } \\
\text { su voz y empieza a hablar una } \\
\text { lengua que parece alemán. Se } \\
\text { instaura un diálogo cómico } \\
\text { entre los dos, basado en el } \\
\text { equívoco lingüístico. Mientras } \\
\text { tanto, Isabella consigue tirar la } \\
\text { carta a Lelio. Este le dice que } \\
\text { Scappino está entreteniendo a } \\
\text { su padre y la joven huye hacia } \\
\text { adentro, cerrando la ventana. } \\
\text { Lelio también se marcha. }\end{array}$ & $\begin{array}{l}\text { Civile, } \\
\text { ventana de la } \\
\text { casa de } \\
\text { Anselmo, } \\
\text { noche }\end{array}$ \\
\hline Escena XXII & $\begin{array}{l}\text { Quedan en la escena Anselmo } \\
\text { y Scappino que continúan el } \\
\text { diálogo cómico. Anselmo llama } \\
\text { a Menica para que le traiga una } \\
\text { luz. Scappino empieza a bailar } \\
\text { y toma de la mano a Anselmo } \\
\text { y le hace bailar. Los dos cantan } \\
\text { y bailan. Luego Scappino se } \\
\text { marcha y Anselmo entra en casa. }\end{array}$ & Civile, noche \\
\hline
\end{tabular}

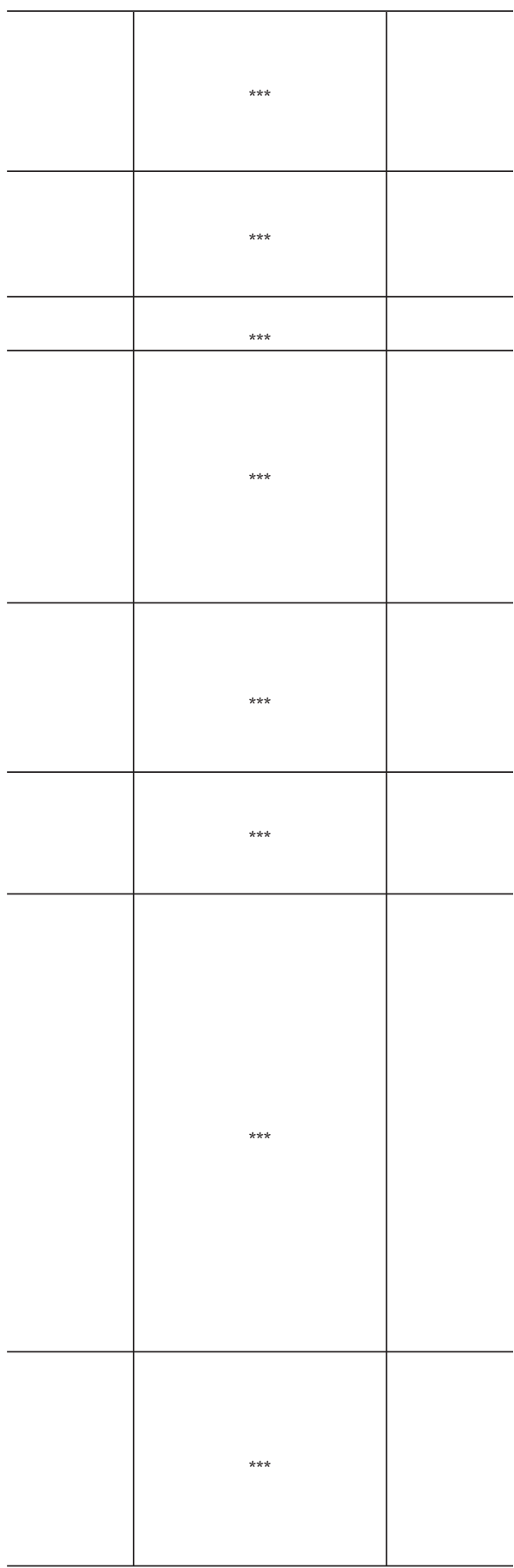


ATTO SECONDO

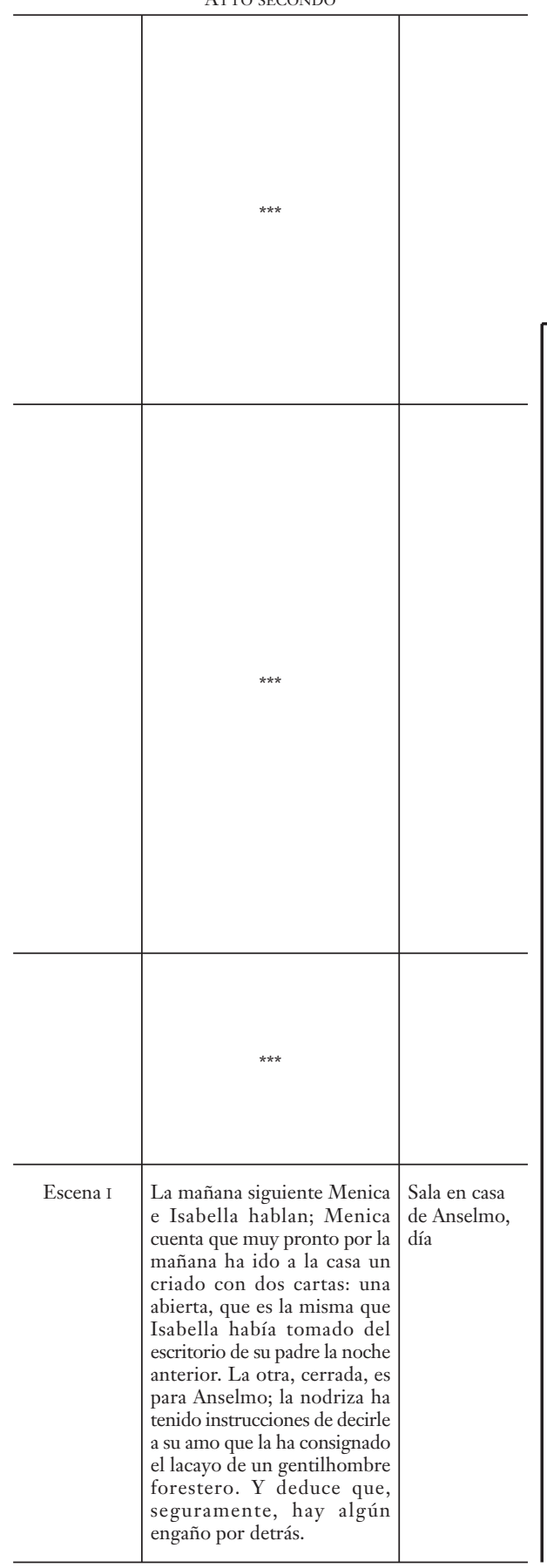

JORNADA SEGUNDA

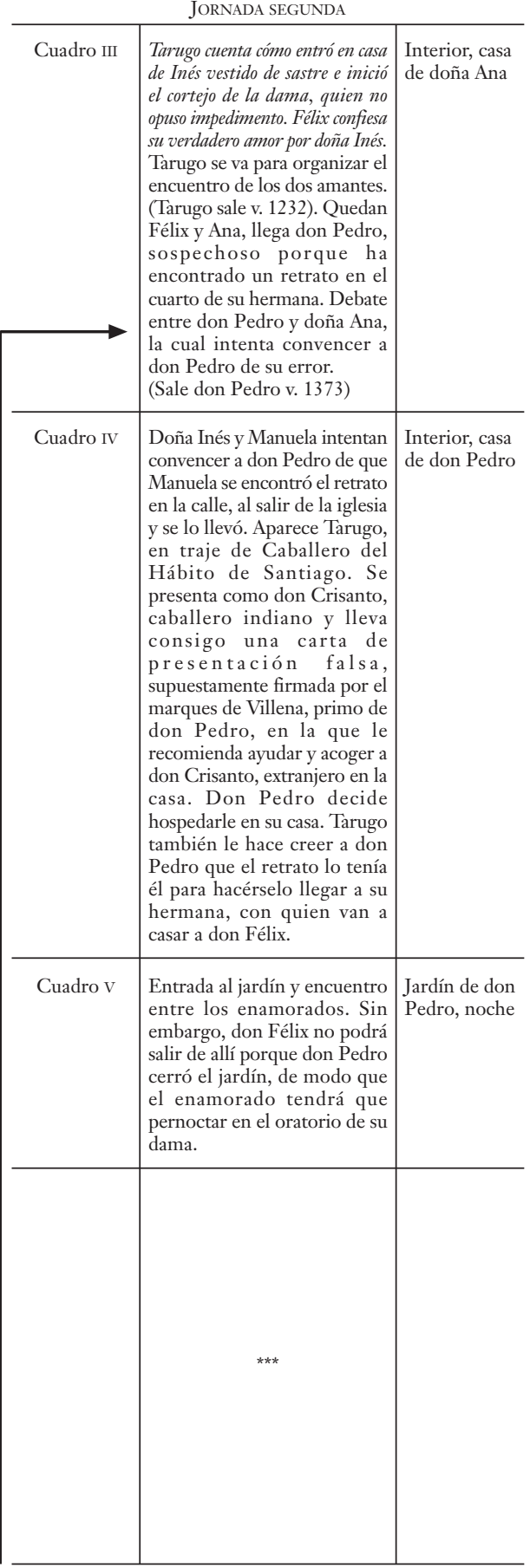




\begin{tabular}{|c|c|c|}
\hline Escena II & $\begin{array}{l}\text { Menica da la carta a Anselmo. } \\
\text { Se trata de una misiva, escritra } \\
\text { por Scappino fingiendo ser } \\
\text { Pancrazio, su hermano que } \\
\text { está en París, pidiendo que } \\
\text { hospede en su casa a un amigo } \\
\text { suyo, Monsù Gian Gian delle } \\
\text { Tantesciose, asegurando que } \\
\text { este compensaría adecuada- } \\
\text { mente la hospitalidad. Ansel- } \\
\text { mo decide acogerle, ignorando } \\
\text { que en realidad Monsù Gian } \\
\text { Gian delle Tantesciose no es } \\
\text { sino el propio Scappino. El } \\
\text { único inconveniente es que } \\
\text { Monsù Gian dice sentir una } \\
\text { tremenda repulsión hacia las } \\
\text { mujeres que le provoca terri- } \\
\text { bles achaques y desmayos. Por } \\
\text { lo tanto, Anselmo obligará a } \\
\text { Menica e Isabella a estar ence- } \\
\text { rradas en una habitación para } \\
\text { que el huésped no se percate } \\
\text { de su presencia. }\end{array}$ & $\begin{array}{l}\text { Sala en casa } \\
\text { de Anselmo, } \\
\text { día }\end{array}$ \\
\hline Escena III & $\begin{array}{l}\text { Anselmo, en la puerta de casa, } \\
\text { espera la llegada del huésped } \\
\text { francés. }\end{array}$ & $\begin{array}{l}\text { Civile / casa } \\
\text { de Anselmo, } \\
\text { día }\end{array}$ \\
\hline Escena IV & $\begin{array}{l}\text { Llega Scappino, en hábito } \\
\text { noble, y empieza a hablar una } \\
\text { jerga que pretende ser francés, } \\
\text { lo que es causa de muchos } \\
\text { equívocos cómicos entre los } \\
\text { dos, que se hacen muchas } \\
\text { reverencias. Scappino le explica } \\
\text { todas sus necesidades: come } \\
\text { poco y bebe solo agua, lo que } \\
\text { alegra mucho a Anselmo. Los } \\
\text { dos acuerdan el precio y } \\
\text { Scappino entra en casa. }\end{array}$ & $\begin{array}{l}\text { Civile / casa } \\
\text { de Anselmo, } \\
\text { día }\end{array}$ \\
\hline Escena $\mathrm{V}$ & $\begin{array}{l}\text { Lelio se pregunta por qué } \\
\text { Scappino se ha vestido de } \\
\text { noble y lleva consigo una carta } \\
\text { firmada por el hermano de } \\
\text { Anselmo. Se abre la puerta de } \\
\text { casa de Taccagni y Lelio se } \\
\text { esconde para escuchar. }\end{array}$ & $\begin{array}{l}\text { Civile / casa } \\
\text { de Anselmo, } \\
\text { día }\end{array}$ \\
\hline Escena VI & $\begin{array}{l}\text { Lelio, al paño, escucha lo que } \\
\text { habla entre sí Anselmo, quien } \\
\text { recapitula lo sucedido con el } \\
\text { extranjero. Lelio se da cuenta, } \\
\text { entonces, de que el extranjero } \\
\text { huésped en casa de Anselmo no } \\
\text { es sino Scappino. Lelio se pone } \\
\text { a hablar con Anselmo y le dice } \\
\text { que sabe que en su casa se hos- } \\
\text { peda un francés. Lelio amonesta } \\
\text { a Anselmo, recordándole que } \\
\text { tiene un hija por casar. }\end{array}$ & $\begin{array}{l}\text { Civile / casa } \\
\text { de Anselmo, } \\
\text { día }\end{array}$ \\
\hline Escena VII & $\begin{array}{l}\text { Menica e Isabella hablan del } \\
\text { forastero y del porqué su padre } \\
\text { quiere que estén encerradas. }\end{array}$ & $\begin{array}{l}\text { Aposento de } \\
\text { Isabella, día }\end{array}$ \\
\hline Escena VIII & $\begin{array}{l}\text { Llega Anselmo quien, } \\
\text { hurgando entre sus cosas de } \\
\text { coser, encuentra una cajiita de } \\
\text { plata. Cuando esta cae y se } \\
\text { abre, se muestra el retrato de }\end{array}$ & $\begin{array}{l}\text { Aposento de } \\
\text { Isabella, día }\end{array}$ \\
\hline
\end{tabular}

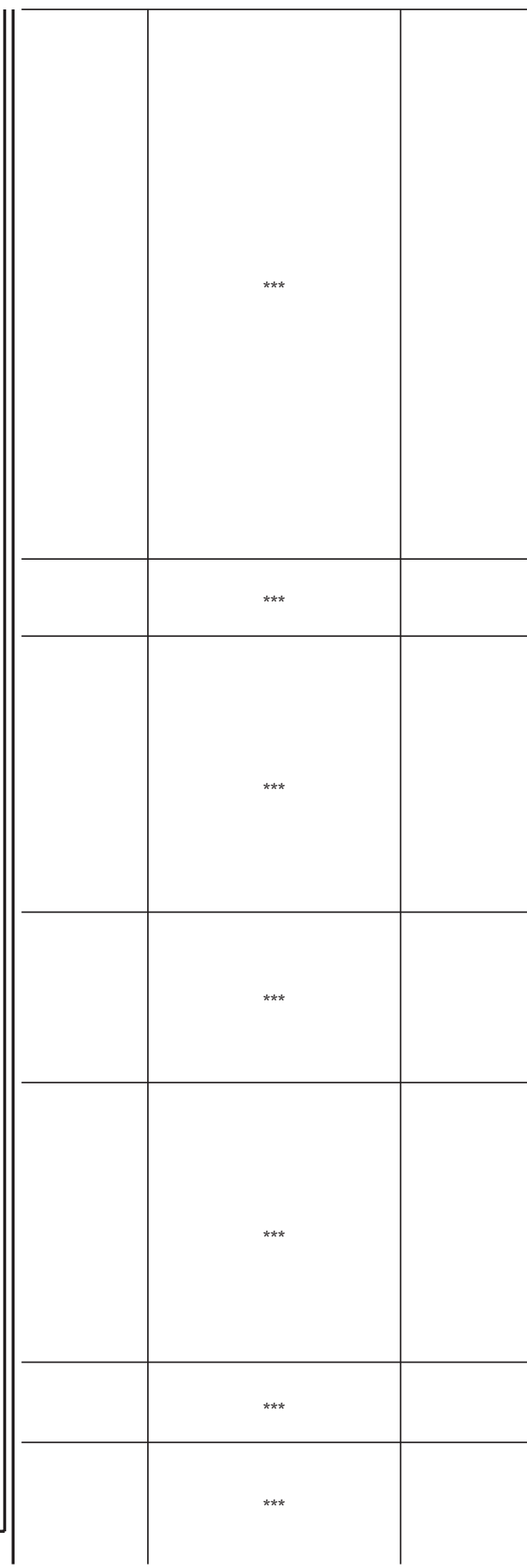




\begin{tabular}{|c|c|c|}
\hline & $\begin{array}{l}\text { Lelio. El viejo se da cuenta de } \\
\text { que Menica e Isabela están de } \\
\text { acuerdo para engañarle y el } \\
\text { motivo por el que Lelio ronda } \\
\text { continuamete su casa. }\end{array}$ & \\
\hline Escena IX & $\begin{array}{l}\text { A las preguntas de Anselmo, } \\
\text { Menica dice que fue ella quien } \\
\text { encontró el retrato en el suelo, } \\
\text { delante de la puerta de casa. } \\
\text { Luego, se lo había dado a } \\
\text { Isabella que lo había puesto } \\
\text { en la canastilla con las cosas } \\
\text { de coser. Isabella le dice a su } \\
\text { padre que no sabe nada del } \\
\text { retrato de Lelio y que, por } \\
\text { cierto, lo ve rondar la casa; } \\
\text { además, ruega a su padre que } \\
\text { le diga algo. Anselmo acusa a } \\
\text { Menica de favorecer la rela- } \\
\text { ción. Isabella le ruega que lo } \\
\text { aleje, pero con discreción, para } \\
\text { que la historia no arruine su } \\
\text { reputación. Los tres discu-ten } \\
\text { qué hacer. Al final, Isabella le } \\
\text { pide que se lo devuelva a Lelio. }\end{array}$ & \\
\hline Escena X & $\begin{array}{l}\text { Sale Scappino/Monsù llaman- } \\
\text { do a Anselmo, que huye para } \\
\text { buscar a Lelio. Isabella se re- } \\
\text { procha por haber dejado el } \\
\text { retrato al alcance de todos. }\end{array}$ & $\begin{array}{l}\text { Sala en el piso } \\
\text { de abajo de } \\
\text { casa de } \\
\text { Anselmo / } \\
\text { Aposento de } \\
\text { Isabella, día }\end{array}$ \\
\hline \multirow[t]{2}{*}{ Escena XI } & $\begin{array}{l}\text { Menica intenta consolar a } \\
\text { Isabella, porque está segura } \\
\text { de que Scappino remediará al } \\
\text { problema. }\end{array}$ & \\
\hline & Escenario vacío & \\
\hline Escena XII & $\begin{array}{l}\text { Scappino encuentra una } \\
\text { solución para explicar la } \\
\text { presencia del retrato. Llama a } \\
\text { Anselmo. }\end{array}$ & $\begin{array}{l}\text { Sala en el piso } \\
\text { de abajo de } \\
\text { casa de } \\
\text { Anselmo, día }\end{array}$ \\
\hline \multirow[t]{2}{*}{ Escena XIII } & $\begin{array}{l}\text { Cuando llega Anselmo le dice, } \\
\text { muy turbado, que ha perdido } \\
\text { un retrato. Anselmo le } \\
\text { responde que él ha encontrado } \\
\text { uno, pero no es de un francés, } \\
\text { sino de un italiano, con quien } \\
\text { incluso tiene una relación de } \\
\text { parentesco, pero no muy } \\
\text { próximo, tanto que podría } \\
\text { darle a su hija como mujer. Al } \\
\text { saber que Anselmo tiene una } \\
\text { hija y que está en casa, } \\
\text { Scappino finge un desmayo. } \\
\text { Al final le dice que se trata del } \\
\text { retrato de un joven que él } \\
\text { busca para casarlo con una } \\
\text { pariente suya. }\end{array}$ & $\begin{array}{l}\text { Sala en el piso } \\
\text { de abajo de } \\
\text { casa de } \\
\text { Anselmo, día }\end{array}$ \\
\hline & Escenario vacío & \\
\hline Escena XIV & $\begin{array}{l}\text { Anselmo, solo, muestra estar } \\
\text { contento de la misoginia de } \\
\text { Monsú. Además le enfada el } \\
\text { hecho de que Lelio preten- } \\
\text { diese cortejar a su hija cuando } \\
\text { ya estaba prometida. }\end{array}$ & $\begin{array}{l}\text { Sala en el piso } \\
\text { de abajo de } \\
\text { casa de } \\
\text { Anselmo, día }\end{array}$ \\
\hline
\end{tabular}

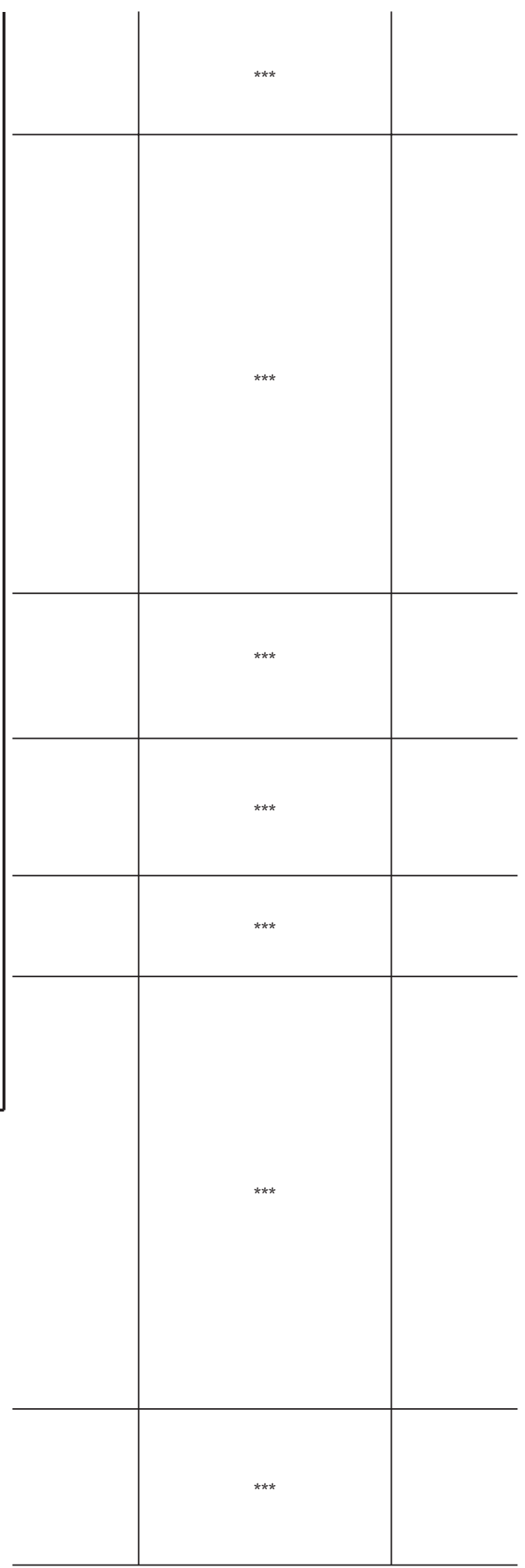




\begin{tabular}{|c|c|c|}
\hline Escena XV & $\begin{array}{l}\text { Soliloquio de Arsilio: el joven } \\
\text { dice que Lelio le ha pedido que } \\
\text { intente hablar con Scappino } \\
\text { para descubrir qué planes tiene } \\
\text { para conseguir el matrimonio } \\
\text { con Isabella. Arsilio quiere } \\
\text { cautivar la simpatía de Lelio } \\
\text { para que este apruebe el } \\
\text { matrimonio con Frasia. }\end{array}$ & Civile, día \\
\hline Escena XVI & $\begin{array}{l}\text { Arsilio se encuentra con } \\
\text { Anselmo mientras este sale de } \\
\text { casa. Arsilio intenta sacarle } \\
\text { informaciones a propósito del } \\
\text { Cavaliere Parigino. Anselmo } \\
\text { acusa a Arsilio de ser un fisgón. } \\
\text { Sin embargo el joven se empeña } \\
\text { en hablar con el francés. } \\
\text { Anselmo, volviendo a entrar en } \\
\text { casa, llama a Monsù Gian. }\end{array}$ & $\begin{array}{l}\text { Civile / casa } \\
\text { de Anselmo, } \\
\text { día }\end{array}$ \\
\hline \multirow[t]{2}{*}{ Escena XVII } & $\begin{array}{l}\text { Anselmo hace las presenta- } \\
\text { ciones y se marcha, cerrando } \\
\text { la puerta, para ir en busca de } \\
\text { Lelio. }\end{array}$ & $\begin{array}{l}\text { Sala en el piso } \\
\text { de abajo de } \\
\text { casa de } \\
\text { Anselmo, día }\end{array}$ \\
\hline & Escenario vacío & \\
\hline Escena XVIII & $\begin{array}{l}\text { Frasia reprocha a su hija la } \\
\text { actitud de la noche anterior y } \\
\text { la joven insiste en que ella no } \\
\text { quería ir. Mientras las dos } \\
\text { discuten llaman a la puerta. } \\
\text { Frasia manda a Cintia a abrir, } \\
\text { pensando que es Arsilio. }\end{array}$ & $\begin{array}{l}\text { Aposento de } \\
\text { Frasia, día }\end{array}$ \\
\hline Escena XIX & $\begin{array}{l}\text { Quien aparece en la puerta es } \\
\text { Anselmo. Frasia le dice que } \\
\text { puede pasar. Cintia, fingiendo } \\
\text { irse, se queda escondida a } \\
\text { escuchar. }\end{array}$ & $\begin{array}{l}\text { Aposento de } \\
\text { Frasia, día }\end{array}$ \\
\hline Escena $\mathrm{Xx}$ & $\begin{array}{l}\text { Anselmo le dice a Frasia que } \\
\text { busca a su hijo Lelio. Los dos } \\
\text { disputan. Finalmente Anselmo } \\
\text { le dice a Frasia que busca a } \\
\text { Lelio por cuenta de un } \\
\text { caballero que se hospeda en su } \\
\text { casa, según el cual, Lelio es } \\
\text { prometido de una pariente } \\
\text { suya. La mujer se enfada mucho } \\
\text { por el poco respeto que le ha } \\
\text { demostrado el hijo al no decirle } \\
\text { nada. Los dos vuelven a altercar. } \\
\text { Anselmo, además, informa a } \\
\text { Frasia de la gran repulsión que } \\
\text { el caballero francés siente hacia } \\
\text { las mujeres y que, por lo tanto, } \\
\text { de ninguna manera Frasia } \\
\text { puede ir a hablar con él. }\end{array}$ & $\begin{array}{l}\text { Aposento de } \\
\text { Frasia, día }\end{array}$ \\
\hline Escena XXI & $\begin{array}{l}\text { Mientras los dos discuten } \\
\text { vuelve Lelio, los dos le cuentan } \\
\text { de manera confusa la historia } \\
\text { del caballero y del retrato. Lelio } \\
\text { se asombra, porque sabe que } \\
\text { su retrato está en manos de } \\
\text { Isabella. Finalmente, Anselmo } \\
\text { informa a Lelio de que Monsù } \\
\text { Gian pregunta por él. Lelio } \\
\text { dice que irá en seguida. Frasia } \\
\text { se empeña en ir también. }\end{array}$ & $\begin{array}{l}\text { Aposento de } \\
\text { Frasia, día }\end{array}$ \\
\hline
\end{tabular}

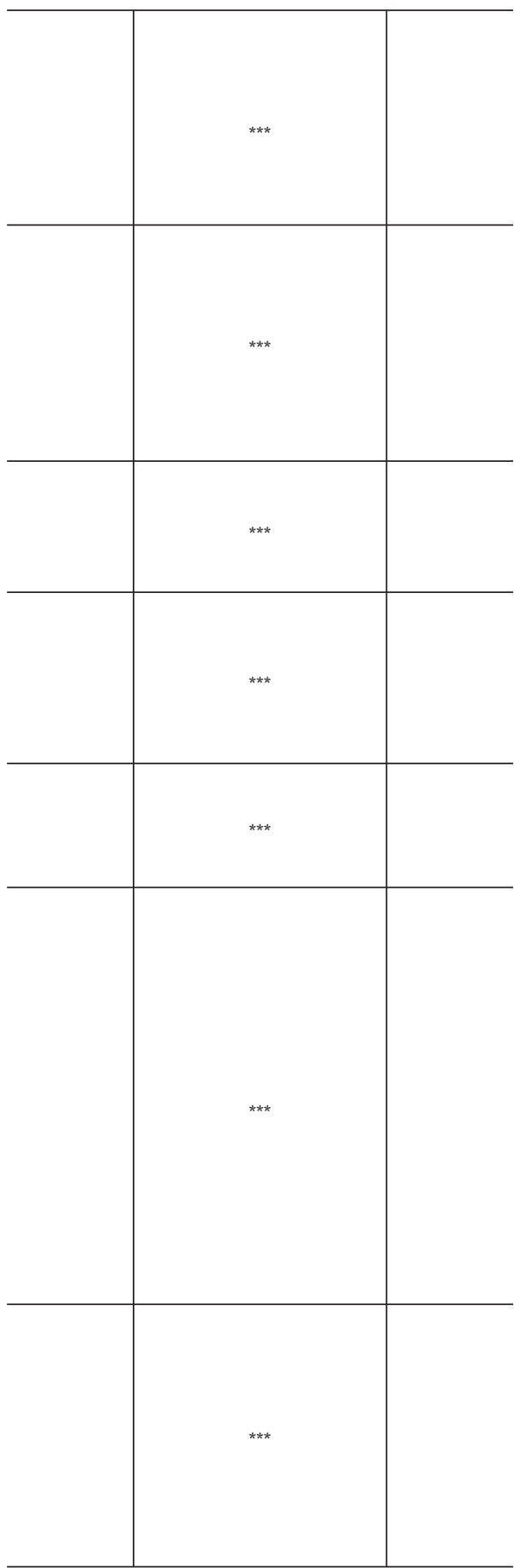




\begin{tabular}{l|l|l}
\hline Escena XXII & $\begin{array}{l}\text { En eso llega Arsilio, muy bien } \\
\text { acogido por Frasia que le dice } \\
\text { que tiene que ir a ver a un } \\
\text { caballero francés a casa de } \\
\text { Anselmo. Arsilio dice que viene } \\
\text { precisamente de verle y le } \\
\text { confirma que tiene una acusada } \\
\text { repulsión hacia las mujeres. En } \\
\text { un aparte, después, le dice a } \\
\text { Lelio que tiene que hablarle a } \\
\text { solas. Lelio dice a Anselmo que } \\
\text { irá dentro de poco. El viejo se } \\
\text { despide. Frasia se ha enterado } \\
\text { de que el francés no es sino } \\
\text { Scappino disfrazado. Arsilio } \\
\text { pide a Frasia que Lelio pueda } \\
\text { ir con él. Ella consiente con tal } \\
\text { de que Arsilio vuelva pronto } \\
\text { para que puedan concertar su } \\
\text { propio matrimonio. }\end{array}$ \\
\hline \multicolumn{2}{|c}{ ATTO TERzo } \\
\hline
\end{tabular}

\begin{tabular}{|c|c|c|}
\hline Escena I & $\begin{array}{l}\text { Lelio y Arsilio hablan. Lelio } \\
\text { dice que su madre estaría } \\
\text { contenta del matrimonio con } \\
\text { Isabella. Arsilio piensa que en } \\
\text { realidad para Frasia sería mejor } \\
\text { que se casara antes Cintia, ya } \\
\text { que su presencia en casa podría } \\
\text { ser un obstáculo a su intención } \\
\text { de volverse a casar. Lelio deja } \\
\text { entender que consentiría al } \\
\text { matrimonio si su madre } \\
\text { escogiese un hombre de bien, } \\
\text { como el mismo Arsilio. } \\
\text { Hablando, llegan cerca de la } \\
\text { casa de Anselmo. Los dos } \\
\text { entran. }\end{array}$ & Civile, noche, \\
\hline Escena II & $\begin{array}{l}\text { En un soliloquio, Scappino } \\
\text { ilustra el plan que ha trazado } \\
\text { para permitir que Isabella y } \\
\text { Menica salgan de la casa sin } \\
\text { que Anselmo se dé cuenta: } \\
\text { Menica e Isabella están } \\
\text { escondidas en el piso de abajo } \\
\text { tapadas y vestidas con unos } \\
\text { trajes que Lelio le ha robado } \\
\text { a Cintia y Frasia, así que } \\
\text { cuando Anselmo las vea será } \\
\text { él mismo quien las echará de } \\
\text { casa. Mientras Anselmo abre } \\
\text { la puerta, simula un desmayo. }\end{array}$ & $\begin{array}{l}\text { Sala en casa } \\
\text { de Anselmo, } \\
\text { noche }\end{array}$ \\
\hline Escena III & $\begin{array}{l}\text { Anselmo se asombra cuando } \\
\text { ve que Monsù no está, como } \\
\text { acostumbra, en la sala del piso } \\
\text { de abajo, sino en la otra; } \\
\text { además cree que ha sufrido un } \\
\text { desmayo. }\end{array}$ & $\begin{array}{l}\text { Sala en casa } \\
\text { de Anselmo, } \\
\text { noche }\end{array}$ \\
\hline Escena IV & $\begin{array}{l}\text { Scappino dice haber sufrido } \\
\text { un desmayo después de que } \\
\text { dos mujeres tapadas han ido } \\
\text { hasta su aposento. Anselmo, } \\
\text { asumiendo que las dos mujeres } \\
\text { son Frasia y Cinzia, decide } \\
\text { despedirlas rápidamente, } \\
\text { preocupado por las condicio- } \\
\text { nes de salud de su huésped. }\end{array}$ & $\begin{array}{l}\text { Sala en casa } \\
\text { de Anselmo, } \\
\text { noche }\end{array}$ \\
\hline
\end{tabular}

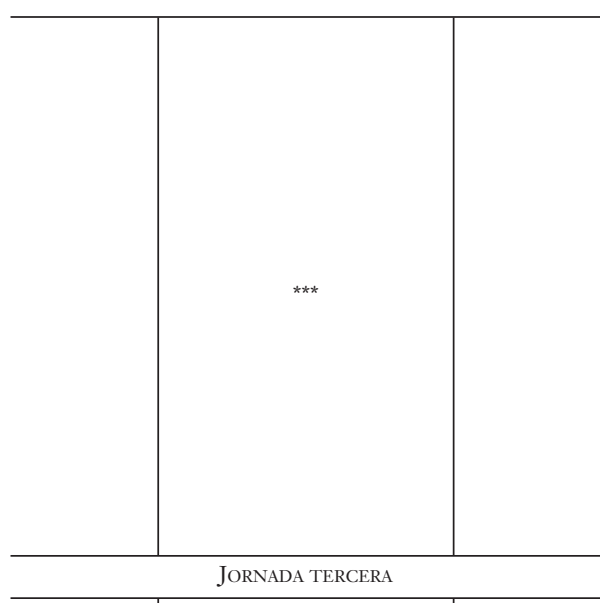

\begin{tabular}{l|l|l}
\hline Cuadro $\mathrm{V}$ & Diálogo entre don Félix y Tarugo & Interior casa
\end{tabular} en el que cuentan cómo han pasado de don Pedro los ocho días que don Félix lleva escondido en el cuarto de Tarugo. Doña Inés avisa a Tarugo y don Félix de que su bermano ya ba descubierto la presencia de un bombre en casa. Tarugo ingenia una astucia para sacar a don Félix sin crear sospechas. Ambos salen sin problemas.

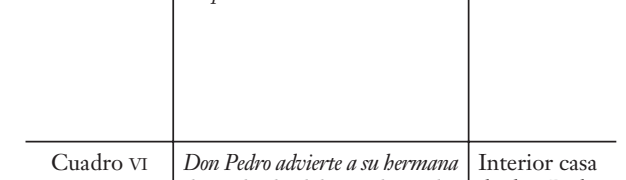

de que ha decidido casarla con don de don Pedro

Diego esa misma noche. Diálogo entre doña Ana y doña Inés. Aquella le cuenta las motivaciones del engaño a su prometido, $y$ doña Inés las noticias del inminente matrimonio forzado. Doña Ana entretiene a don Pedro y don Diego para retrasar la boda y dar tiempo a don Félix a evitarla.

Diálogo entre Tarugo y don Félix Calle, noche en la calle. (v. 2770) Sale la criada de doña Ana para advertirles de la próxima boda de doña Inés si él no lo remedia. Tarugo ingenia otra astucia para sacar a las mujeres de casa.

Tarugo consigue sacar a las mujeres de casa, fingiendo que son busconas. 


\begin{tabular}{|c|c|c|c|c|}
\hline Escena VI & $\begin{array}{l}\text { Anselmo entra y ve a las dos } \\
\text { mujeres y las echa de casa } \\
\text { creyendo que son Frasia y } \\
\text { Cintia. En eso, alguien llama } \\
\text { a la puerta. Anselmo ve que es } \\
\text { Lelio con Arsilio. }\end{array}$ & $\begin{array}{l}\text { Aposento de } \\
\text { Anselmo, } \\
\text { noche }\end{array}$ & $\begin{array}{l}\text { Don Félix y las mujeres, } \\
\text { tapadas, se disponen a ir a casa } \\
\text { de doña Ana. Don Pedro y don } \\
\text { Diego los encuentran en el } \\
\text { camino y deciden escoltarlos. }\end{array}$ & Calle, noche \\
\hline Escena VIII & $\begin{array}{l}\text { Anselmo sale de la puerta y } \\
\text { entrega a Lelio y Arsilio a las } \\
\text { dos mujeres tapadas, sin darse } \\
\text { cuenta de que debajo del } \\
\text { embozo se esconden su hija } \\
\text { Isabella y Menica. Además, el } \\
\text { viejo les dice a los dos que } \\
\text { cuando hayan traído a las } \\
\text { mujeres a casa, vuelvan allí } \\
\text { para hablar con Monsù Gian. }\end{array}$ & $\begin{array}{l}\text { Civile / casa } \\
\text { de Anselmo, } \\
\text { noche }\end{array}$ & & \\
\hline Escena IX & $\begin{array}{l}\text { Una vez solo, Anselmo se } \\
\text { maravilla de que Frasia, habi- } \\
\text { tualmente muy habladora, no } \\
\text { haya abierto la boca. }\end{array}$ & $\begin{array}{l}\text { Casa de } \\
\text { Anselmo, } \\
\text { noche }\end{array}$ & $* * *$ & \\
\hline Escena $\mathrm{X}$ & $\begin{array}{l}\text { Scappino oye a Anselmo que } \\
\text { vuelve hacia la sala y finge otro } \\
\text { desmayo. }\end{array}$ & $\begin{array}{l}\text { Sala en casa } \\
\text { de Anselmo, } \\
\text { noche }\end{array}$ & $* * *$ & \\
\hline \multirow[t]{2}{*}{ Escena XII } & $\begin{array}{l}\text { Anselmo, en un soliloquio, } \\
\text { dice que va a ver si Menica e } \\
\text { Isabella están "ferme e chete". }\end{array}$ & $\begin{array}{l}\text { Sala en casa } \\
\text { de Anselmo, } \\
\text { noche }\end{array}$ & \multirow[t]{2}{*}{$* * *$} & \\
\hline & Escenario vacío & & & \\
\hline \multirow[t]{2}{*}{ Escena XIII } & $\begin{array}{l}\text { Scappino supone que en ese } \\
\text { mismo momento Anselmo } \\
\text { habrá alcanzado su aposento } \\
\text { para encontrarlo vacío. Se } \\
\text { siente muy contento de haber } \\
\text { favorecido el amor entre Lelio } \\
\text { e Isabella, obstaculizado por } \\
\text { la avaricia del viejo. }\end{array}$ & $\begin{array}{l}\text { Aposento de } \\
\text { Anselmo, } \\
\text { noche }\end{array}$ & \multirow[t]{2}{*}{$* * *$} & \\
\hline & Escenario vacío & & & \\
\hline Escena XIV & $\begin{array}{l}\text { Anselmo, gritando, dice que } \\
\text { no encuentra a su hija y a } \\
\text { Menica y va a buscarlas en } \\
\text { cada rincón de la casa. }\end{array}$ & $\begin{array}{l}\text { Aposento de } \\
\text { Anselmo, } \\
\text { noche }\end{array}$ & $* * *$ & \\
\hline Escena XV & $\begin{array}{l}\text { Scappino, temiendo la ira de } \\
\text { Anselmo, huye por una puerta } \\
\text { secreta. }\end{array}$ & $\begin{array}{l}\text { Aposento de } \\
\text { Anselmo, } \\
\text { noche }\end{array}$ & $* * *$ & \\
\hline
\end{tabular}




\begin{tabular}{|c|c|c|c|c|}
\hline Escena XVII & $\begin{array}{l}\text { Isabella está muy contenta de } \\
\text { casarse con Lelio y este, aun } \\
\text { más, porque fue el proprio } \\
\text { Anselmo quien le dio su mano. } \\
\text { Isabella se muestra arrepentida } \\
\text { por haber engañado a su } \\
\text { padre, pero Frasia, Arsilio y } \\
\text { Lelio la convencen de que ha } \\
\text { sido una acción necesaria. } \\
\text { Lelio va en busca de Anselmo } \\
\text { para que bendiga la unión. }\end{array}$ & $\begin{array}{l}\text { Sala en casa } \\
\text { de Frasia, } \\
\text { noche }\end{array}$ & $* * *$ & \\
\hline Escena XVIII & $\begin{array}{l}\text { Llega Scappino y todos le } \\
\text { piden informaciones de } \\
\text { Anselmo. Scappino les infor- } \\
\text { ma de que el viejo se está } \\
\text { dirigiendo precisamente a casa } \\
\text { de Frasia. Lelio se prepara } \\
\text { para cogerlo. }\end{array}$ & $\begin{array}{l}\text { Sala en casa } \\
\text { de Frasia, } \\
\text { noche }\end{array}$ & $\begin{array}{l}\text { Finalmente, aparecen todos } \\
\text { en escena y doña Ana confiesa } \\
\text { a su prometido el engaño al } \\
\text { que ha sido sometido, tras lo } \\
\text { cual, don Pedro, viendo que } \\
\text { no ha habido un daño real a } \\
\text { su honor, reconoce su error y }\end{array}$ & $\begin{array}{l}\text { Interior de la } \\
\text { casa de doña } \\
\text { Ana, noche }\end{array}$ \\
\hline Escena XIX & $\begin{array}{l}\text { Menica anuncia la llegada de } \\
\text { Anselmo. Todos concuerdan } \\
\text { que es mejor que Isabella se } \\
\text { retire. }\end{array}$ & $\begin{array}{l}\text { Sala en casa } \\
\text { de Frasia, } \\
\text { noche }\end{array}$ & $\begin{array}{l}\text { hermana con don Félix y él se } \\
\text { casa con su prometida doña } \\
\text { Ana. También los criados } \\
\text { Tarugo y Manuela acabarán } \\
\text { casados. }\end{array}$ & \\
\hline Escena XX & $\begin{array}{l}\text { Llega Anselmo, desesperado } \\
\text { y azorado. Lelio le explica lo } \\
\text { sucedido: las mujeres que } \\
\text { Anselmo le entregó no eran } \\
\text { Frasia y Cintia, sino Menica } \\
\text { e Isabella. Insiste diciendo que } \\
\text { él ya le había dicho que "il } \\
\text { tanto badare alle donne non } \\
\text { giova, com'esse hann'umore } \\
\text { diverso". Finalmente Anselmo } \\
\text { pregunta por su hija. }\end{array}$ & $\begin{array}{l}\text { Sala en casa } \\
\text { de Frasia, } \\
\text { noche }\end{array}$ & $* * *$ & \\
\hline Escena XXI & $\begin{array}{l}\text { Llega Isabella quien se } \\
\text { arrodilla ante su padre. Lelio } \\
\text { pide a Anselmo la mano de } \\
\text { Isabella. El viejo se ve obligado } \\
\text { a aceptar a regañadientes el } \\
\text { matrimonio entre su hija y } \\
\text { Lelio. }\end{array}$ & $\begin{array}{l}\text { Sala en casa } \\
\text { de Frasia, } \\
\text { noche }\end{array}$ & $* * *$ & \\
\hline Escena XXII & $\begin{array}{l}\text { Menica intenta disculparse } \\
\text { con Anselmo. }\end{array}$ & $\begin{array}{l}\text { Sala en casa } \\
\text { de Frasia, } \\
\text { noche }\end{array}$ & $* * *$ & \\
\hline Escena XXIII & $\begin{array}{l}\text { Monsù revela su identidad a } \\
\text { Anselmo y le revela también } \\
\text { que fue él quien le dio el } \\
\text { retrato a Isabella, entrando en } \\
\text { casa disfrazado de chincagliere; } \\
\text { y que también escribió la carta } \\
\text { firmada por Pancrazio } \\
\text { Taccagni, explicándole cómo } \\
\text { lo hizo todo. Al llegar Frasia } \\
\text { dice que ya es hora de } \\
\text { concertar las bodas entre Lelio } \\
\text { e Isabella y entre ella misma } \\
\text { y Arsilio. Finalmente Menica } \\
\text { dice que quiere casarse con } \\
\text { Scappino; pero Scappino } \\
\text { rehúsa. Tambien hay que casar } \\
\text { a Cintia; Menica va a llamarla. }\end{array}$ & $\begin{array}{l}\text { Sala en casa } \\
\text { de Frasia, } \\
\text { noche }\end{array}$ & $* * *$ & \\
\hline
\end{tabular}




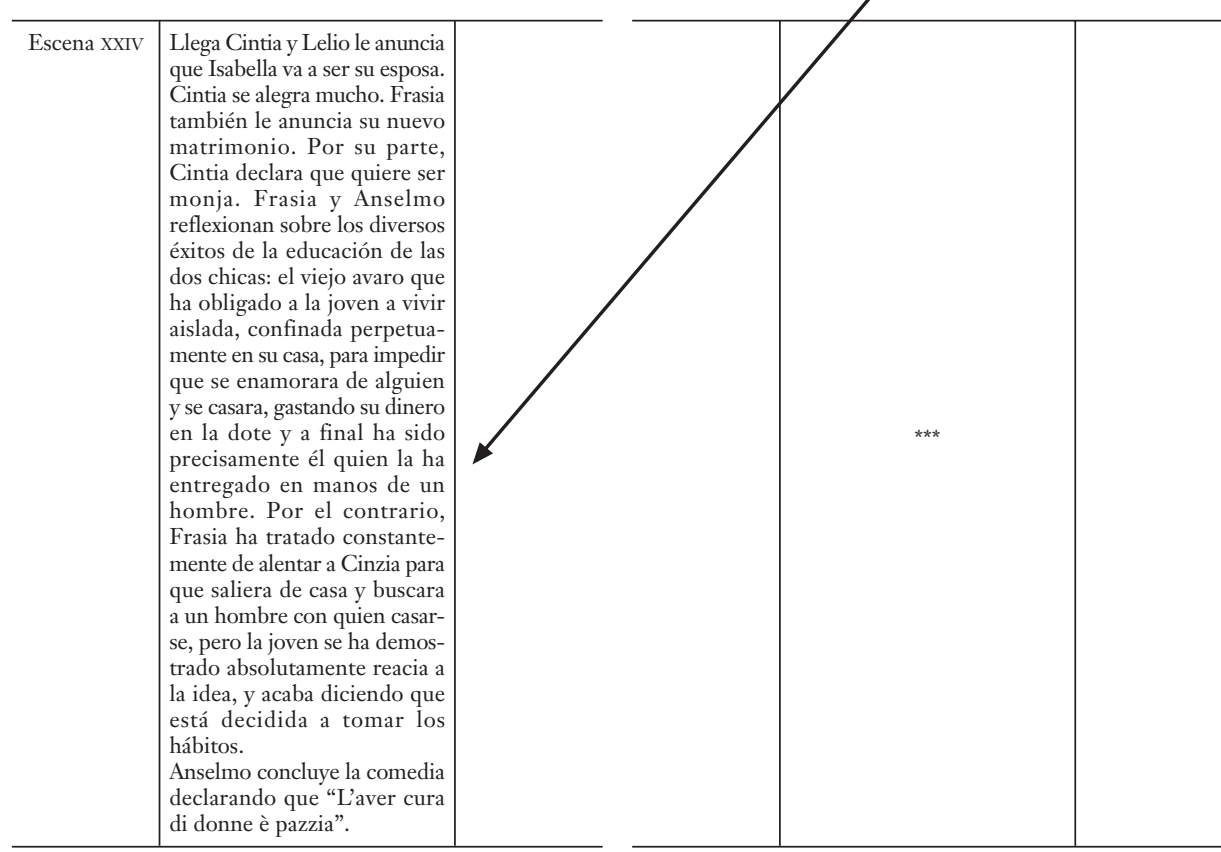

\section{OBRAS CITADAS}

Allacci, Leone. Drammaturgia di Lione Allacci, accresciuta e continuata fino all'anno MDCCLV. Venecia: Giambattista Pasquali, 1755.

Alviti, Roberta. "La fortuna de No puede ser guardar una mujer de Agustín Moreto en la commedia dell'arte", en prensa.

Alviti, Roberta, y Debora Vaccari. "Moreto en Italia: primeros datos y dos ejemplos de reescritura". Paradigmas teatrales en la Europa moderna: circulación e influencias (Italia, España y Francia, siglos XVI-XVIII). Eds. Christophe Couderc y Marcella Trambaioli. Toulouse: Presses Universitaires du Midi, 2016. 185-209.

Archivo del teatro pregoldoniano. http://www.usc.es/goldoni/. Fecha de acceso: $15 / 02 / 2019$.

Bencini, Mariano. Il vero Giovan Battista Fagiuoli e il teatro in Toscana a' suoi tempi. Firenze: Fratelli Bocca, 1884.

Binni, Walter. "Nelli e Fagiuoli". L'Arcadia e il Metastasio. Firenze: Sansoni, 1968. 207-43. 
Decroisette, François. "Le rôle de l'aparté dans le dialogue de G. B. Fagiuoli". Théâtre en Toscane. La comedie (XVIe, XVII et XVIII siècles). Ed. Michel Plaisance. Paris: Presses Universitaires de Vincennes, 1981. 157-87.

Fagiuoli, Giovan Battista. Commedie di Giovan Battista Fagiuoli, fiorentino. Vol. 3. Lucca: Salvatore e Giandomenico Marescandoli, 1755. 1-183.

Foggi, Rossella. Giovan Battista Fagiuoli (Firenze, 24 giugno 1660-12 luglio 1742): cultura e umorismo di un uomo del popolo alla corte dei Medici: un'eredità conservata. Firenze: Alberto Bruschi, 1993.

Moreto, Agustín. No puede ser. Eds. María Luisa Lobato y María Ortega. Comedias de Agustín Moreto. Segunda parte de comedias. Vol. 5. Dir. María Luisa Lobato, coord. Marcella Trambaioli. Kassel: Reichenberger, 2016. 49-246.

Pecori, Giampaolo, ed. Il Fagiuoli. Poeta alla corte di Gian Gastone de' Medici. Firenze: Libreria Editrice Fiorentina, 1979.

Ruano de la Haza, José María. "La escenificación de la Comedia". Los teatros comerciales del siglo XVII y la escenificación de la Comedia. Eds. José María Ruano de la Haza y John J. Allen. Madrid: Castalia, 1994. 247-607.

Santoyo, Julio-César. "Traducciones y adaptaciones teatrales: ensayo de tipología", Cuadernos de Teatro Clásico 2 (1989): 95-112.

Serralta, Frédéric. "El tipo de 'galán suelto': del enredo al figurón”. Cuadernos de teatro clásico. La comedia de capa y espada 1 (1988): 83-93.

Turchi, Roberta. La commedia italiana del Settecento. Firenze: Sansoni, 1985.

Turchi, Roberta. "Da Fagiuoli a Goldoni. Storie di Cicisbei". Goldoni "avant la lettre": esperieneze teatrali pregoldoniane. Ed. Javier Gutiérrez Carou. Venezia: Lineadacqua, 2015. 213-27. 